\title{
ALTERNATIVE MONETARY POLICY RULES: A COMPARISON WITH HISTORICAL SETTINGS FOR THE UNITED STATES, THE UNITED KINGDOM, AND JAPAN
}

Bennett T. McCallum

Working Paper 7725

http://www.nber.org/papers/w7725

\author{
NATIONAL BUREAU OF ECONOMIC RESEARCH \\ 1050 Massachusetts Avenue \\ Cambridge, MA 02138 \\ June 2000
}

This paper has been prepared for the Economic Quarterly of the Federal Reserve Bank of Richmond. For comments, suggestions, or assistance I am indebted to Miguel Casares, Martin Gervais, Marvin Goodfriend, Robert Hetzel, Yash Mehra, Allan Meltzer, Athanasios Orphanides, Edward Nelson, and Jeffrey Walker. The views expressed herein are those of the author and not necessarily those of the National Bureau of Economic Research.

(C) 2000 by Bennett T. McCallum. All rights reserved. Short sections of text not to exceed two paragraphs, may be quoted without explicit permission provided that full credit, including (C) notice, is given to the source. 
Alternative Monetary Policy Rules: A Comparison with Historical Settings

for the United States, the United Kingdom, and Japan

Bennett T. McCallum

NBER Working Paper No. 7725

June 2000

JEL No. E52, E42, E31

\title{
ABSTRACT
}

This paper conducts counterfactual historical analysis of several monetary policy rules by contrasting actual settings of instrument variables with values that would have been specified by the rules in response to prevailing conditions. Of particular interest is whether major policy mistakes, judged ex post, would have been prevented by candidate rules. The rules studied include those of Taylor and McCallum, previously considered by Alison Stuart, plus several additional combinations of instrument and target variables. The time spans examined are 1962-1998 for the U.S. and U.K., and 1972-1998 for Japan. In addition to various substantive findings, the paper develops several methodological arguments. A surprising result is that rules' messages are evidently more dependent upon the specification of their instrument than their target variable.

\author{
Bennett T. McCallum \\ Graduate School of Industrial Administration \\ Carnegie Mellon University \\ Pittsburgh, PA 15213 USA \\ Tel. (412) 268-2347 Fax (412) 268-7357 \\ and NBER \\ bm05@andrew.cmu.edu
}


Recent years have witnessed an upsurge of interest among monetary policy analysts in the topic of simple and explicit rules for monetary policy. In this recent work it is presumed that such rules would not be followed literally and slavishly by central banks, but that they could be consulted for indicative purposes - perhaps by providing a starting point for policy discussions. Tangible evidence of this interest is provided by publications based on two 1998 conferences, both titled "Monetary Policy Rules," sponsored by the National Bureau of Economic Research (NBER) and by the Sveriges Riksbank in collaboration with Stockholm University's Institute for International Economic Studies (IIES). ${ }^{1}$ Most of the work in these papers is based on some variant of the now-famous Taylor rule, introduced in Taylor (1993), which specifies settings of a nominal interest rate instrument in response to observed or predicted values of inflation and the output gap (i.e., the percentage difference between output and its reference value $\left.^{2}\right) .{ }^{3}$ Some of the studies consider alternative instrument or target variables, ${ }^{4}$ and very recently some criticisms of the Taylor rule have been expressed by Orphanides (1998,1999), Meltzer (1999), and others. Accordingly, the purpose of the present paper is to conduct counterfactual historical analysis of the type utilized by Stuart (1996) and Taylor (1999b), and to compare and consider the messages provided by Taylor's rule with others featuring alternative instrument and/or target variables.

\footnotetext{
${ }^{1}$ Proceedings of the NBER conference have been published in Taylor (1999a); papers from the Riksbank-IIES conference appear in the June 1999 issue of the Journal of Monetary Economics.

${ }^{2}$ This reference value is defined variously, in different studies, as the trend or capacity or potential or natural-rate or market-clearing value of output.

${ }^{3}$ In many of the studies, a lagged value of the interest rate is also included as a determinant of the current value, thereby reflecting interest rate smoothing behavior.
} 
The type of historical analysis developed by Stuart (1996) and Taylor (1999b) consists of contrasting actual settings of instrument variables during some historical time span with the values that would have been specified by particular rules in response to prevailing conditions. Discrepancies or agreements between rule-specified and actual values can then be evaluated, in light of ex-post judgements concerning macroeconomic performance during the span studied, to yield tentative conclusions concerning the merits of the various rules. Of particular interest is whether major policy mistakes, judged expost, would have been prevented by adherence to some of the candidate rules. Stuart (1996) conducted such comparisons for Taylor's rule and also one promoted by McCallum $(1987,1993)$ that features a monetary base instrument and a nominal-income growth target. ${ }^{5}$ The sample period utilized by Stuart was 1985.1-1996.2 for the United Kingdom. In the present study experiences will be considered for the United States, the United Kingdom, and Japan with the time span beginning in the early 1960s or (for Japan) 1970s and extending through 1998.4. The investigation will also extend the range of rules considered by combining interest rate and monetary base instruments with both Taylor-type and nominal-income target variables.

It should be said explicitly that no suggestion is intended to the effect that historical analysis of the Stuart-Taylor type represents the only useful approach to policyrule evaluation. Most of the author's own work, in fact, has involved simulations with quantitative structural macroeconomic models (e.g., McCallum, 1988, 1993; McCallum and Nelson, 1999a,b). The position advanced is merely that the Stuart-Taylor type of

\footnotetext{
${ }^{4}$ See, for example, McCallum and Nelson (1999a, 1999b).

${ }^{5}$ In its growth-rate version, considered exclusively here and by Stuart (1996), McCallum's rule is similar (though not identical) to one promoted by Meltzer (1987).
} 
study can also be useful, in addition to simulations with structural models. In this regard, it is important to be clear about the nature of the exercise involved, i.e., to appreciate its limitations and strengths_- both of which are considerable. Accordingly, these will be reviewed in Section 2, immediately following the paper's first application of the StuartTaylor procedure.

The outline of the paper is as follows. In Section 1 the alternative rules are specified, notation is established, and some general issues are discussed. Applications to the United States, the United Kingdom, and Japan are then conducted in Sections 2-4. Issues concerning the specification of target variables are taken up in Section 5 and issues related to instrument variables in Section 6. A brief conclusion is presented in Section 7.

\section{Specification of Rules}

The well-known Taylor rule can be expressed as follows:

$$
\mathrm{R}_{\mathrm{t}}=\overline{\mathrm{r}}+\Delta \mathrm{p}_{\mathrm{t}}^{\mathrm{a}}+0.5\left(\Delta \mathrm{p}_{\mathrm{t}}^{\mathrm{a}}-\pi^{*}\right)+0.5 \tilde{\mathrm{y}}_{\mathrm{t}}
$$

Here $\mathrm{R}_{\mathrm{t}}$ is the short-term nominal interest rate that the central bank in question uses as its instrument or "operating target," i.e., the interest rate over which it exerts control at a daily or weekly frequency. Next, $\overline{\mathrm{r}}$ is the long-run average real rate of interest, $\Delta \mathrm{p}_{\mathrm{t}}^{\mathrm{a}}$ is an average of recent inflation rates (or a forecast value), and $\pi^{*}$ is the central bank's target inflation rate. Finally, $\widetilde{\mathrm{y}}_{\mathrm{t}}$ is a measure of the output gap, the percentage difference between actual and capacity output values. In Taylor's original application (1993), the values $\overline{\mathrm{r}}=2$ and $\pi^{*}=2$ were specified, expressing the belief that 2 percent per annum is an approximation to the long-run average real rate of interest in the United States, and that 2 percent per annum is a reasonable specification for the Federal Reserve's target 
inflation rate. ${ }^{6}$ Also, in Taylor (1993) the measure used for $\Delta \mathrm{p}_{\mathrm{t}}^{\mathrm{a}}$ is the average of GDP deflator inflation rates over the past four quarters, while capacity output is represented by a linear trend for the log of real GDP fit to quarterly observations for the years 19851992. In Taylor (1999b), the Hodrick-Prescott (1997) filter is used instead to generate residuals from "trend" that are taken to represent $\widetilde{y}_{t}$. The rule suggests, of course, that monetary policy should be tightened (by an increase in $R_{t}$ ) when inflation exceeds its target value and/or output exceeds capacity.

Subsequent applications of the Taylor rule have modified or extended formula (1) in several ways. Some have used proxies for expected future inflation in place of $\Delta \mathrm{p}_{\mathrm{t}}^{\mathrm{a}}$ while others have done something similar for $\widetilde{y}_{t}$ or used $\widetilde{y}_{t-1}$ instead. A common and major change is to include $R_{t-1}$ on the right-hand side as a determinant of $R_{t}$; this adjustment is intended to reflect the practice of interest rate smoothing, which is widely believed to be prevalent in the behavior of many central banks.

An important line of investigation has been pioneered by Orphanides (1997, 1999), who has attempted to base rule calculations on values of $\Delta \mathrm{p}_{\mathrm{t}}$ (inflation) and $\widetilde{y}_{\mathrm{t}}$ that were actually available to central bank policymakers at the time that historical instrument settings were chosen. Orphanides (1997) recognizes that current-period values for $\widetilde{y}_{t}$ could not be known until after the end of period $t,{ }^{7}$ and also emphasizes the fact that macroeconomic data is often substantially revised after its initial reporting. In Orphanides (1999) it is argued that these problems are so severe that adherence to the

\footnotetext{
${ }^{6}$ It is not necessary that constants be used for these values, but they are in Taylor (1993) and for additional postwar periods in Taylor (1999b).

${ }^{7}$ This type of operationality issue has been emphasized by McCallum and Nelson (1999a) and McCallum (1999a).
} 
Taylor rule would not have prevented the inflation of the 1970s, as claimed by Taylor (1999b). Partly for reasons to be mentioned in Section 5 and partly because of the difficulty of doing otherwise, the present study will be based on data available in June 1999, not on real time data of the type recommended by Orphanides.

The rule proposed by McCallum $(1987,1988,1993)$ can be expressed as follows:

$$
\Delta \mathrm{b}_{\mathrm{t}}=\Delta \mathrm{x}^{*}-\Delta \mathrm{v}_{\mathrm{t}}^{\mathrm{a}}+0.5\left(\Delta \mathrm{x}^{*}-\Delta \mathrm{x}_{\mathrm{t}-1}\right) .
$$

Here $\Delta b_{t}$ is the change in the log of the adjusted monetary base, i.e., the growth rate of the base between periods $\mathrm{t}-1$ and $\mathrm{t}$. The term $\Delta \mathrm{x} *$ is a target growth rate for nominal GDP, $\Delta \mathrm{x}_{\mathrm{t}}$ being the change in the log of nominal GDP. This target value $\Delta \mathrm{x}^{*}$ is specified as $\pi^{*}+\Delta y^{*}$, where $\Delta y^{*}$ is the long-run average rate of growth of real GDP. The second term on the right-hand side of (2), $\Delta \mathrm{v}^{\mathrm{a}}$, is the average growth of base velocity over the previous 16 quarters, $\mathrm{v}_{\mathrm{t}}=\mathrm{x}_{\mathrm{t}}-\mathrm{b}_{\mathrm{t}}$ being the $\log$ of base velocity. This term is intended to reflect long-lasting changes in the demand for the monetary base that occur because of technological developments or regulatory changes (presumed to be permanent); it is not intended to reflect cyclical conditions. These conditions are responded to by the final term, which prescribes that base growth is adjusted upward (i.e., policy is loosened) when $\Delta \mathrm{x}_{\mathrm{t}-1}$ falls short of $\Delta \mathrm{x}^{*}$. In McCallum $(1988,1993)$ values other than 0.5 are considered for the coefficient attached to $\Delta \mathrm{x}^{*}-\Delta \mathrm{x}_{\mathrm{t}-1}$ and variants of (2) that respond to discrepancies of the level type, rather than the growth rate type, are investigated. Here, however, we shall limit our attention to the particular formulation given in (2).

A bit of discussion needs to be given to the topic of units of measurement. In previous studies by McCallum, growth rate variables such as $\Delta \mathrm{x}_{\mathrm{t}}$ have been measured as changes in logs. Therefore such variables reflect quarterly changes, not annualized, and 
in fractional (rather than percentage) units. Accordingly, such variables need to be multiplied by 400 to be commensurate with similar variables as measured by Taylor and in most papers concerned with policy rules. Similar comments pertain as well to interest rate measures. To maintain consistency among the different rules considered, we shall here report all results in terms of annualized percentages, rather than in the quarterly fractional units previously used in the work of McCallum.

Another detail of rule specification concerns timing. In (2), both of the variables on the right-hand side are based on variables realized in period t-1 or earlier; i.e., currentperiod values are not utilized. The reason, as suggested in footnote 6 , is to make the rule specification realistically operational. In Taylor's studies, the inflation variable $\Delta \mathrm{p}_{\mathrm{t}}^{\mathrm{a}}$ is typically measured as referring only to previous-period values but it is assumed that $\widetilde{\mathrm{y}}_{\mathrm{t}}$ pertains to period t. Since it is rather clear that current-quarter values of real GDP cannot be observed until well into the next quarter, in the present study $\widetilde{y}_{t}$ will be measured as the value of the output gap variable (however measured) pertaining to the previous quarter.

Clearly, the Taylor and McCallum rules differ in terms of both instrument and target variables. ${ }^{8}$ There is no obvious reason, however, why these should be paired in any particular combination. It would be quite natural, that is, to consider a rule with an interest rate instrument and a nominal income growth target. Similarly, it would be reasonable to consider a rule with a base growth instrument and a Taylor-style target

\footnotetext{
${ }^{8}$ Here I am using the term "target variable" to refer to a variable that the policy rule responds to in a manner designed to reduce its deviations from some reference path. Svensson (1999) objects to this usage, preferring to reserve the word "target" for
} 
specification. Accordingly, the investigation that follows will also consider, in addition to (1) and (2), rules of the form

$$
\mathrm{R}_{\mathrm{t}}=\overline{\mathrm{r}}+\Delta \mathrm{p}_{\mathrm{t}}^{\mathrm{a}}-0.5\left(\Delta \mathrm{x}^{*}-\Delta \mathrm{x}_{\mathrm{t}-1}\right)
$$

and

$$
\Delta \mathrm{b}_{\mathrm{t}}=\Delta \mathrm{x}^{*}-\Delta \mathrm{v}_{\mathrm{t}}^{\mathrm{a}}-0.5 \mathrm{~h}_{\mathrm{t}},
$$

where we define the "hybrid" target variable $\mathrm{h}_{\mathrm{t}}=\left(\Delta \mathrm{p}_{\mathrm{t}}^{\mathrm{a}}-\pi^{*}+\widetilde{\mathrm{y}}_{\mathrm{t}}\right) .{ }^{9}$ Thus rule (4) features responses to the same macroeconomic conditions as in Taylor's rule (1) but with a base instrument. Examination of the results involving (1)- (4) should then enable one to determine whether differences in policy advice offered by (1) and (2) are due primarily to their different instruments or targets.

\section{$\underline{\text { 2. United States }}$}

We begin with the case of the United States. For $x_{t}, y_{t}$, and $p_{t}$ we use the logarithms of nominal GDP, real (chain-linked) GDP, and their ratio. The monetary base is the series computed by the St. Louis Fed, which incorporates adjustments for changes in reserve requirements. In addition, an adjustment for sweep accounts has been made for $1994-1998 .^{10}$ Finally, $R_{t}$ is the federal funds rate averaged over the quarter. All variables except $R_{t}$ are seasonally adjusted. The series are taken from the FRED data base of the Federal Reserve Bank of St. Louis. In what follows, $\Delta \mathrm{p}_{\mathrm{t}}^{\mathrm{a}}=0.25\left(\Delta \mathrm{p}_{\mathrm{t}-1}+\Delta \mathrm{p}_{\mathrm{t}-2}\right.$ $\left.+\Delta \mathrm{p}_{\mathrm{t}-3}+\Delta \mathrm{p}_{\mathrm{t}-4}\right)$ while for $\widetilde{\mathrm{y}}_{\mathrm{t}}$ we report the percentage excess ( in period $\mathrm{t}-1$ ) of output

variables appearing in loss functions. For a brief discussion see McCallum and Nelson (1999b).

${ }^{9}$ The term "hybrid" was used for this variable by Hall and Mankiw (1994).

${ }^{10}$ Specifically, 0.10 times the cumulative total of sweeps of transaction deposits into MMDAs, reported by FRED, are added to the adjusted base series. Here 0.10 represents the marginal reserve requirement ratio. 
over a "trend" reference value provided by the Hodrick-Prescott (HP) filter, as in Taylor (1999a). The effect of the latter choice will be discussed below, in Section 5.

Figure 1 plots values of $R_{t}$ implied by the Taylor rule (1) with $\pi^{*}=2$ and $\bar{r}=2$ together with actual values over $1960-1998 .{ }^{11}$ From an inspection of this figure, it can be seen that the actual interest rate was lower than the rule-implied value throughout the 1970s, indicating that monetary policy was too loose, according to the rule. Beginning in 1981 policy was then too tight until 1987, the first year considered in Taylor's original study (1993). Over 1987-1995 policy was about right, according to the figure, but since 1996 has been somewhat too tight.

As mentioned above, it is important to recognize the limitations and virtues of the type of comparison provided by Figure 1. If in a particular period the actual value of $R_{t}$ was lower than the rule-specified value, then the rule's indication is that policy was too loose in that period, given the prevailing conditions. There is no suggestion that the actual setting of $\mathrm{R}_{\mathrm{t}}$ in that period was too low unconditionally. Indeed, the presumption of Stuart (1996) and Taylor (1999b), which is adopted here, is that prevailing inflation would have been lower during the 1970s if Taylor's rule had been followed in practice. So the $R_{t}$ settings that would have been appropriate, according to rule (1), would have been lower than those indicated by the solid line in Figure $1 .{ }^{12}$ Thus the solid line in Figure 1 does not pretend to represent an optimal or even desirable path for $\mathrm{R}_{\mathrm{t}}$ over the period. But that does not prevent the comparison of the two lines from indicating that, conditional upon prevailing conditions, actual $\mathrm{R}_{\mathrm{t}}$ values were set lower than the rule

\footnotetext{
${ }^{11}$ Because our data base is for 1960.1-1998.4, rule-implied values begin with 1961.2 because of the lags needed to determine $\Delta \mathrm{p}_{\mathrm{t}}^{\mathrm{a}}$.
} 
would have called for in virtually every period during the 1970s. From the standpoint of rule (1), therefore, monetary policy was too loose during the 1970s. That is the only type of conclusion provided by Figure 1, and other such plots presented below.

Thus the principal weakness of this type of comparison is that it does not provide an indication of what an "optimal" policy would have been or even of what time path crucial variables would have followed under the rule being examined. But there is an offsetting virtue. Any designation of optimality—indeed, any specification of how $R_{t}$ or other variables would have evolved historically under any specified policy rule—is necessarily dependent upon the specific model of the economy used to predict how $\Delta \mathrm{p}_{\mathrm{t}}$ and $\widetilde{y}_{t}$ would have responded to $R_{t}$ settings. The Stuart-Taylor procedure, by contrast, does not require adoption of any specific model. This is a highly significant virtue, because there is no professional agreement concerning the proper specification of the "correct" model of the economy. ${ }^{13}$

We now return to the main line of analysis and move on to rule (2). For its application, we take $\Delta \mathrm{x}^{*}=5$, combining a 2 percent inflation target with an assumed long-run average output growth rate of 3 percent per year. ${ }^{14}$ The comparison of base growth values implied by rule (2) with actual historical values is presented in Figure $2 .^{15}$

${ }^{12}$ If $\Delta \mathrm{p}^{\mathrm{a}} \mathrm{t}$ had been lower in each period, the $\mathrm{R}_{\mathrm{t}}$ values prescribed by (1) would have been lower.

${ }^{13}$ For an elaboration on this last point, see McCallum (1999, pp. 1490-1). As mentioned in the introduction, the purpose of the present digression is not to object to counterfactual simulation studies, based on specific models, but only to argue that different procedures have different strengths and weaknesses.

${ }^{14}$ The value of 3 percent for output growth was used in McCallum $(1987,1988)$ together with an inflation target of 0 percent - and in subsequent studies. The actual average over 1960-1998 was 2.97 percent.

${ }^{15}$ Rule values begin with 1964.2 because of the lags needed to calculate $\Delta \mathrm{v}_{\mathrm{t}}^{\mathrm{a}}$. 
There it will be seen that policy was too loose - actual base growth was greater than specified by the rule — during the second half of the 1960s and much too loose throughout the 1970s. This discrepancy was gradually reduced between 1981 and 1987. Then policy was slightly too loose during 1990-1992 and too tight during 1994-1995, according to the rule. Since 1995 it has been about right, on average, although the final observation of 1998 suggests slightly excessive base growth at that date.

Figure 3 gives results for rule (4), which combines the base instrument (as in (2)) with the hybrid target variable (as in (1)). Somewhat surprisingly, the broad overall characterization of the results can be described with the same words used for the base rule (2). The main difference is that the rule-indicated path of $\Delta b_{t}$ has less quarter-toquarter variability than in Figure 2. The reason, evidently, is that (4) does not respond to quarter-to-quarter movements in the growth rate of output (real GDP), which are quite volatile. The basic message provided by the hybrid target variable is much the same as that provided by nominal GDP growth because the HP filter yields quite small values for the output gap, as will be illustrated below. Therefore, $h_{t}$ and $\Delta x_{t}$ behave alike except for the volatility introduced into the latter by the $\Delta \mathrm{y}_{\mathrm{t}}$ component.

Results with rule (3), featuring the interest rate instrument with a nominal GDP growth target variable, are shown in Figure 4. Now the broad overall signals are much like those of Figure 1, the Taylor rule, except with a more erratic path because of the output growth component of the target variable. So the comparison among the four figures suggests that the choice of an instrument variable matters more for the trend of monetary policy than the choice of a target variable. It should be emphasized, however, that this preliminary conclusion pertains only to the nominal GDP growth and hybrid 
variables, with the output gap component of the latter determined by the HP filter method.

\section{United Kingdom}

Before delving more deeply into the comparisons among the rules, let us now look at the basic cases using data for the United Kingdom. Again $\mathrm{x}_{\mathrm{t}}, \mathrm{y}_{\mathrm{t}}$, and $\mathrm{p}_{\mathrm{t}}$ are nominal GDP, real GDP, and their ratio. For the monetary base $b_{t}$ we use the Bank of England's M0 measure, seasonally adjusted, which requires no adjustments for reserve requirements because the latter are small enough to be negligible. ${ }^{16}$ The interest rate utilized is a one-month treasury-bill rate, averaged over the quarter. For the United Kingdom, we use a value of 2.25 for $\overline{\mathrm{r}}, 2$ for $\pi^{*}$, and 2.25 for $\Delta \mathrm{y}^{*}$. Thus $\Delta \mathrm{x}^{*}=4.25$. The output gap measure is the percentage departure of real GDP from trend, obtained from the residuals from a regression of the log of real GDP on a linear trend fitted over the years 1960-1998.

Results using the Taylor rule (1) are shown in Figure 5. The indication there is that monetary policy was much too loose during the 1970s, with the rule calling for an interest rate of 38 percent in 1975.3, as compared with an actual value of $10.4 .{ }^{17}$ From 1983 through 1987 policy was slightly too tight, according to the rule, and since 1987 has been just about right, except perhaps in 1994.

\footnotetext{
${ }^{16}$ Data for M0 are published by the Bank of England for 1969.3-1998.4. Earlier values were obtained from Capie and Webber (1985) and spliced on.

${ }^{17}$ Of course if rule (1) had been followed throughout, actual inflation would probably have been much less severe and the values of $R_{t}$ indicated by the rule would have been much lower.
} 
The McCallum rule (2) gives a somewhat different story, as is shown in Figure 6. It agrees that policy was much too loose during the 1970s, but suggests that it stayed too loose most of the time until 1990 (when the U.K. entered the European Union's exchange rate mechanism in October, dropping out in September 1992). Since 1992, policy was slightly loose, according to Figure 6, until 1997 when it became just about right. The main difference in the messages of Figures 5 and 6 is that the latter suggests that policy was too loose during the mid-1980s. Ex-post, this suggestion seems correct, as U. K. inflation rose prior to 1990 to excessive heights_-probably as a consequence of the episode of "shadowing the D-mark" that occurred during 1986-1988.

As in the case of the United States, the messages from rules (3) and (4) tend to agree when the instrument used is the same, not the target variable. Thus in Figure 7 we have base growth figures implied by rule (4), with the hybrid target variable, and the policy messages are much the same as in Figure 6, but with less quarter-to-quarter variability of the indicated $\Delta \mathrm{b}_{\mathrm{t}}$ values. And in Figure 8, plotted for an interest instrument and a $\Delta \mathrm{x}_{\mathrm{t}}$ target, we find substantial agreement with the indications of Figure 5, which pertains to the Taylor rule. Agreement is incomplete, however, since this rule does not call for looser policy in the mid-1980s.

\section{Japan}

In the case of Japan, our rules will be applied only to the period 1972.1-1998.4, rather than a time span beginning in the early 1960s. The reasons are that Japanese data for constructing a monetary base series does not exist for years prior to 1963; that Japan kept a fixed exchange rate with the U. S. dollar prior to 1971; and that there was a 
marked break in the growth rate of Japanese real GDP around that time. ${ }^{18}$ For the subsequent period we use $\overline{\mathrm{r}}=3$, a higher value than for the United States or the United Kingdom, because real output growth was higher in Japan. Nevertheless, for $\Delta \mathrm{x}^{*}$ we adopt a value of 5, corresponding to an average long run real output growth rate of 3 percent and (again) a target inflation rate of $\pi^{*}=2$ percent. In measuring the output gap $\widetilde{y}_{t}$ we cannot use either the HP filter or a linear trend because output in 1998 was quite far below capacity, in the judgement of most observers. Instead, we have measured the fractional gap over 1972.1-1992.2 as the residual from a regression of the log of real GDP on a linear trend (fitted to 1972.1-1992.4 observations), and have assumed that trend or capacity output grew at a rate of 2.5 percent per annum since 1992.2 . This procedure yields a gap that grows to a figure of 11.2 percent for 1998.4.

The Bank of Japan now publishes four monthly data series on the monetary base, beginning in 1970, with and without adjustments for seasonality and reserve requirement changes. The monthly series with both adjustments was averaged to generate values for 1970.1-1998 and data from McCallum (1993) was spliced on to cover 1963.1-1969.4. (Values prior to 1967.4 were not used in the study, however.) For $\mathrm{R}_{t}$ the overnight call rate (uncollateralized) was used and official GDP statistics provided the basis for the remaining variables.

Application of Taylor's rule (1) to Japan for 1972.1-1998.4 is depicted in Figure 9. There the indications are that policy should have been much tighter during 1973-1974 and somewhat tighter over 1975-1978. Since then, policy was slightly too tight most of the time over 1982-1987, and then about right until 1994. Since then it has been too tight

\footnotetext{
${ }^{18}$ For these reasons McCallum (1993) begins its rule study with the quarter 1972.1.
} 
most of the time, but not in 1997. At the end of 1998, the call rate was almost 4 percentage points too high, the Taylor rule-indicated value being -3.6 percent. Of course, the latter value is not feasible, but it indicates that the rule calls for much more stimulative policy than actually prevailed in late 1998.

This last message is also provided by the base rule (2), as shown in Figure 10, but to an even greater extent. Indeed, this rule suggests that monetary policy has been too tight most of the time since the middle of 1990. Like (1), it points to a too-loose stance over 1972-1978. Interestingly, in light of the "asset-price bubble" of the late 1980s, Figure 10 indicates that monetary policy was slightly too loose during 1986-1988.

We now turn to rules (3) and (4). In the case of Japan, Figure 11 shows that the latter again gives much the same signals as does the other rule with the $\Delta b_{t}$ instrument, rule (2). And again the hybrid target variable yields a smoother path for base growth than does (2). As for the interest rate rule with a nominal GDP growth target, rule (3), the Figure 12 results are more similar to those in Figure 9 than in Figure 10. The extent to which rule (3) calls for added stimulus in recent years is even less than in Figure 9, however. The rule does call for easier policy in the last half of 1998, but finds policy about right during 1995-1997.

\section{Issues Concerning Target Variables}

One of the main preliminary indications of the foregoing discussion is that rather similar policy signals are provided by rules with $\Delta \mathrm{x}_{\mathrm{t}}$ and $\mathrm{h}_{\mathrm{t}}$ target variables, provided that the instrument variable is the same. This notion needs to be strongly qualified, however, as will now be discussed. The main point is that the similarity of $\Delta \mathrm{x}_{\mathrm{t}}$ and $\mathrm{h}_{\mathrm{t}}$ signals

observed in Sections 2-4 depends upon the use of output gap measures that do not yield 
large numerical magnitudes over the time span studied. In the case of the United States, the measure used was based on residuals from the HP filter. The standard deviation of these values over 1960-1998 is only 1.63, in percentage points. If instead the output gap measure was based on residuals from a linear trend (for the log of real GDP), the standard deviation would be 4.15 and the impact of the gap measure would be significantly greater. In that case the Taylor rule vs. actual comparison, comparable to Figure 1, would be as shown in Figure 13. Here the monetary policy message is not drastically different from that of Figure 1 for the subperiod 1966-1990, although the need for tighter policy during the 1970s would be more clearly indicated. But for the early 1960s and the late 1990s the message would be quite different, with lower interest rates indicated by the gap based on the log-linear detrending. According to the Figure 13 version of the Taylor rule, the federal funds rate was too high by about 300 basis points throughout 1995-1998!

It is the author's belief that reliance of a policy rule upon any output gap measure is risky, for different measures give quite different values and there is at present no professional consensus on an appropriate measure—or even a concept. Linear detrending depends rather sensitively on the time period selected for fitting of the trend, as is illustrated in Figure 14 where gap measures based on log-linear trends fitted over 19601998 and 1980-1998 are shown, together with values based on the HP filter. It might be suggested that this problem could be alleviated by quadratic detrending, but quadratic trends are themselves rather sensitive to the time period selected for fitting. The latter claim is supported by Figure 15, which shows gap measures based on quadratic trends for the $\log$ of real U.S. GDP fitted over the time periods 1960.1-1998.4 and 1980.1-1998.4. As can be seen, these measures often differ by as much as 3 percentage points. 
With respect to the HP filter, the problem is that this procedure produces a "trend" that is so flexible that it follows the time path of actual GDP rather closely, thereby yielding measures of the output gap that would appear to underestimate (in absolute terms) the economically relevant gap values. ${ }^{19}$ To illustrate this point, Figure 16 shows how the HP filter handles U.S. observations on real GDP during the 1920s and 1930s. According to this figure, U.S. output had fully returned to "trend" by 1934 and the incidence of above-trend output was approximately the same as below-trend output during the 1930s, suggesting that the Great Depression actually did not occur!

More fundamentally, McCallum and Nelson (1999a) argue that any gap measure based on an output detrending procedure, which excludes the effects of current shocks from the measured gap, is conceptually inappropriate. The point is that (e.g.) positive technology shocks serve to increase the capacity or natural-rate value of output, not the value of actual output relative to the latter; but many univariate detrending procedures presume just the opposite. To overcome this difficulty, McCallum and Nelson (1999a) propose a measure based on the assumption of a Cobb-Douglas production function and utilizing values of manhours employed per member of the civilian workforce. This measure treats technological change appropriately, at least arguably, but relies upon debatable assumptions about labor supply and does not have a well-defined zero value. As mentioned above, the recent work of Orphanides $(1997,1999)$ has attracted considerable attention. In the earlier of the cited papers, Orphanides constructed data series for 1987-1992 reflecting values of macroeconomic variables that were actually

\footnotetext{
${ }^{19}$ The present discussion presumes adoption of the standard value of 1600 for the HP filter's smoothing coefficient in work with quarterly data.
} 
available at the time of FOMC (Federal Open Market Committee) policy decisions in the past. These series do not, accordingly, reflect data revisions and measurements that have taken place after the FOMC meetings at which instrument settings (usually values of the federal funds rate) were actually decided. In this context, the measurement of "potential" or "natural-rate" output is especially problematical. This study indicated that the magnitude of the informational problems were serious enough that "real-time policy recommendations differ widely from those obtained with the revised published data employed [by researchers] later on" (Orphanides, 1997, p. 3). The broad overall policy messages offered by the Taylor rule for 1987-1992 are not overturned, however, by the results of the 1997 study.

The results in Orphanides (1999) are more drastic. In this later paper, the time span studied goes back until 1966.1 and so includes the major inflationary buildup and continuation that Taylor (1999b) refers to as "The Great Inflation." Orphanides's dramatic conclusion is that adherence to Taylor's rule throughout the period would not, in constrast to Taylor's (1999b, pp. 338-9) contention, have prevented the Great Inflation.

Developing an appropriate evaluation of Orphanides's (1999) analysis is not a trivial undertaking. Certainly the data reconstruction represents a major contribution to economic policy analysis, and Orphanides's arguments are very carefully constructed and exposited. In my judgement, they do not imply that simple monetary policy rules cannot be useful when constrained by real-time data availability. Instead, I believe, the (1999) study shows in a dramatic fashion that reliance on an inappropriate concept of potential (or reference) output can be ruinous, i.e., can result in a monetary policy rule that is counterproductive. But some rules do not rely upon such measures, as the examples of 
Sections 2-4 above illustrate. ${ }^{20}$ Also, the truly dramatic results in Orphanides (1999) stem from a potential output concept revision, rather than a data revision. Thus, although the data-revision problem is not of negligible significance, it is not as profound as a quick reading of Orphanides (1999) might suggest. To the author, it seems satisfactory to abstract from that problem for the purposes of the present study.

Given the foregoing argument, and also the findings of Sections 2-4, a natural step would be to investigate the performance of rules that use inflation as the target variable, i.e., the cyclical variable responded to by the instrument. Accordingly, we now present figures based on the two policy rules

$$
\mathrm{R}_{\mathrm{t}}=\overline{\mathrm{r}}+\Delta \mathrm{p}_{\mathrm{t}}^{\mathrm{a}}+0.5\left(\Delta \mathrm{p}_{\mathrm{t}}^{\mathrm{a}}-\pi^{*}\right)
$$

$$
\Delta \mathrm{b}_{\mathrm{t}}=\Delta \mathrm{x}^{*}-\Delta \mathrm{v}_{\mathrm{t}}^{\mathrm{a}}-0.5\left(\Delta \mathrm{p}_{\mathrm{t}}^{\mathrm{a}}-\pi^{*}\right),
$$

which can be compared with (1) and (4). The results are shown in Figures 17-22. For the United States, the interest rate rule in Figure 17 calls for $R_{t}$ values quite close to those of Figure 1. Also, the base growth rule in Figure 18 yields settings for $\Delta b_{t}$ that are rather close to those shown in Figure 3, in which the rule responds to the hybrid target variable. Likewise, the plots in Figures 19 and 20 for the United Kingdom are rather similar to those in Figures 5 and 7. In the case of Japan, however, the policy advice for recent years provided by the inflation-target rule in Figure 21 is quite different than that in Figure 9. In particular, in the absence of an output gap signal, rule (5) calls for $R_{t}$ settings somewhat higher than actual values during 1997 and 1998. The base rule (6) results in

${ }^{20}$ This conclusion is basically consistent with Orphanides's warning against "activist" policy rules, by which he means rules that place emphasis on measures of the level of an output gap concept. Orphanides finds that a rule featuring "natural growth targeting," 
Figure 22 remain more stimulative than the actual record for recent years, but to a lesser extent than in Figure 11.

One attractive aspect of the inflation target variable $\Delta \mathrm{p}_{\mathrm{t}}^{\mathrm{a}}$ relative to the nominal income variable $\Delta \mathrm{x}_{\mathrm{t}-1}$ is that the former features smaller quarter-to-quarter movements and therefore imparts a smoother, less choppy path to the instrument variables in (5) and (6), in comparison to (2) and (3). One reason for this, certainly, is that $\Delta \mathrm{p}_{\mathrm{t}}^{\mathrm{a}}$ reflects fourquarter averaging while $\Delta \mathrm{x}_{\mathrm{t}-1}$ does not. Accordingly, it should be of some interest to see how the nominal income variable would perform if averaged over periods t-1 through t-4. Results with that modification are presented in Figures 23-28. In these plots, it can be seen that the choppiness of rules with a nominal GDP growth target is reduced substantially, although the implied instrument settings remain slightly more variable than with the inflation target. Are there any compensating advantages of the averaged $\Delta \mathrm{x}$ values relative to the averaged $\Delta \mathrm{p}$ values? For the United States and the United Kingdom, the policy advice seems to be basically the same in Figures 23-26 as in Figures 17-20. In the case of Japan, however, the nominal income targets in Figures 27-28 give more stimulative signals than with inflation targeting (Figures 21-22), which seems desirable. But the magnitude is not very large.

\section{Issues Concerning Instrument Variables}

One of the more surprising aspects of the results in Sections 2-4 is that the policy diagnoses provided by the various rules seem to be more dependent upon the instrument

which is rather similar to nominal income growth targeting as in rules (2) or (3) above, is not strongly subject to the difficulties that he emphasizes. 
variable utilized than upon the choice of target variable. This indication seems inconsistent with most analysts' beliefs about monetary policy design. Reflection upon the role and nature of the rules makes this finding understandable, however, in the following manner. First, the way in which the rules are utilized in a study such as the present one implies that the rule-specified instrument settings are actually being used as magnitudes of indicator variables, not instruments. That is, one could view the resulting values for quarterly settings of $R_{t}$ or $\Delta b_{t}$ as intermediate targets to be obtained by day-today or week-to-week manipulation of other variables actually serving as the central bank's instrument. ${ }^{21}$ Second, the policy stance-i.e., degree of tightness or easerepresented by rule-specified settings of $R_{t}$ or $\Delta b_{t}$ depends upon the magnitude of those variables relative to some reference value that can vary from period to period. In the case of the Taylor rule (1) the reference value is $\overline{\mathrm{r}}+\Delta \mathrm{p}_{\mathrm{t}}^{\mathrm{a}}$, which serves to convert $\mathrm{R}_{\mathrm{t}}$ movements into movements in a real interest rate measured relative to $\bar{r}$, since $R_{t}-$ $\left(\overline{\mathrm{r}}+\Delta \mathrm{p}_{\mathrm{t}}^{\mathrm{a}}\right)=\left(\mathrm{R}_{\mathrm{t}}-\Delta \mathrm{p}_{\mathrm{t}}^{\mathrm{a}}\right)-\overline{\mathrm{r}}$. With the McCallum rule (2), the reference value for $\Delta \mathrm{b}_{\mathrm{t}}$ is $\Delta \mathrm{x}^{*}-\Delta \mathrm{v}_{\mathrm{t}}^{\mathrm{a}}$. In this case, $\Delta \mathrm{b}_{\mathrm{t}}-\left(\Delta \mathrm{x}^{*}-\Delta \mathrm{v}_{\mathrm{t}}^{\mathrm{a}}\right)$ reflects the difference between $\Delta \mathrm{b}_{\mathrm{t}}$ and the value of base growth that would yield an inflation rate of $\pi^{*}$ if output growth were equal to its long-run average value and base velocity growth were equal to its average over the past 16 quarters (a value that is implicitly being used as a forecast of the average over the indefinite future).

\footnotetext{
${ }^{21}$ A study that proceeds in this fashion is McCallum (1995), which considers how the U.S. federal funds rate could be manipulated on a week-to-week basis to hit quarterly intermediate targets for monetary base growth with the latter set so as to keep nominal income growth close to a specified target value.
} 
In each case, in other words, there is a necessary reference variable that must be specified to convert raw values of $R_{t}$ or $\Delta b_{t}$ into measures of monetary ease or tightness. ${ }^{22}$ Accordingly, the precise specification of these reference variables is of considerable importance to a rule's performance. If rules are to be relatively simple, it is necessary that the specification of these reference values be simple - hence Taylor's specification of a constant "equilibrium" real rate of interest or McCallum's constant "long-run growth rate of output." Evidently, however, the properties of any rule will depend critically upon how these reference values are specified. Consequently, it would appear that future research should perhaps devote more attention to this aspect of policy rule specification. To date, most of the attention of researchers has instead been directed to the choice among target variables, details of their specification, and the magnitude of coefficients attached to them.

\footnotetext{
${ }^{22}$ This statement applies to all of the rules, of course, not just (1) and (2).
} 


\section{$\underline{\text { 7. Conclusion }}$}

Let us close with a brief summary of the findings developed above, based on historical policy-rule studies for the United States, the United Kingdom, and Japan. The basic results come from comparisons of actual values with rule specifications regarding either interest-rate or monetary-base instrument settings, together with nominal GDP growth or Taylor-style hybrid (inflation plus output gap) target variables. For the United States, all of the rules considered would have called for tighter monetary policy during the 1970s, although the base-instrument rules would have done so more strongly than those with the Fed's actual funds-rate instrument. There is some disagreement among the rules concerning the 1980 s and 1990s, although all of the candidate rules indicate that policy has not been highly inappropriate since 1987, at least. For the United Kingdom, the various rules agree regarding the excessive inflation of the 1970s, but the baseinstrument rules suggest that policy was too loose during the middle and late 1980s whereas the interest-instrument rules do not. In the case of Japan, interest centers on the record since 1990. Most of the examined rules indicate that policy was too tight in 1998, but the base rules suggest excessive tightness for the entire period 1990-1998, while the interest rate rules do not. All in all, the recommendations provided by the base rules seem somewhat more appropriate from an ex-post perspective.

Some of the study's suggestions are methodological, rather than substantive. In particular is it argued that reliance on output gap measures is risky, because various measures of potential or natural-rate output levels differ widely and there is no professional consensus regarding the most appropriate measure or even concept to be used. Most univariate detrending procedures, which are frequently utilized, would seem 
to be fundamentally inappropriate, because they assign the effects of technology shocks primarily to the gap between output and its reference value, rather than to the latter variable itself. Omission of the output gap term from a rule with the hybrid target converts it into an inflation targeting rule; it is shown that such rules give good advice in most of the episodes. So, too, do nominal income growth rules that average recent values.

A somewhat surprising finding is that rules' messages are evidently more dependent upon the specification of their instrument than their target variable. ${ }^{23}$ This finding can be understood as resulting from the necessity of specifying a reference value, relative to which instrument settings are implicitly compared, in representing policy tightness or ease. For rules to be sufficiently simple, these reference-value specifications must themselves be simple, but different implicit assumptions about macroeconomic behavior are accordingly built into the rule. The paper suggests, accordingly, that investigation of these implicit assumptions could be an important topic for future research concerned with alternative monetary policy rules.

\footnotetext{
${ }^{23}$ Provided that strong dependence upon an output gap measure is avoided.
} 


\section{References}

Capie, Forrest, and Alan Weber. A Monetary History of the United Kingdom, 1870-1982, Vol. 1. London: George Allen and Unwin, 1985.

Clarida, Richard, Jordi Gali, and Mark Gertler. "Monetary Policy Rules in Practice: Some International Evidence,” European Economic Review, vol. 42 (June 1998), pp. 1033-1067.

Hall, Robert E., and N. Gregory Mankiw. "Nominal Income Targeting," in N. Gregory Mankiw, ed., Monetary Policy. Chicago: University of Chicago Press, 1994.

Hodrick, Robert J., and Edward C. Prescott. "Postwar U.S. Business Cycles: An Empirical Investigation," Journal of Money, Credit, and Banking, vol. 29 (February 1997), pp. 1-16.

Judd, John P., and Glenn D. Rudebusch. “Taylor's Rule and the Fed:1970-1997,” Federal Reserve Bank of San Francisco Economic Review (No. 3, 1998), pp. 3-16.

Kozicki, Sharon. “How Useful Are Taylor Rules for Monetary Policy?” Federal Reserve Bank of Kansas City Economic Review, vol.84 (Second Quarter, 1999), pp. 5-33. McCallum, Bennett T. "The Case for Rules in the Conduct of Monetary Policy: A Concrete Example," Federal Reserve Bank of Richmond Economic Review, vol. 73 (September/October 1987), pp. 10-18. . "Robustness Properties of a Rule for Monetary Policy," Carnegie-Rochester Conference Series on Public Policy, vol. 29 (Autumn 1988), pp. $173-203$. "Specification and Analysis of a Monetary Policy Rule for Japan," Bank of Japan Monetary and Economic Studies, vol. 11 (November 1993), pp. 1-45. 
. "Monetary Policy Rules and Financial Stability," in

Kuniho Sawamoto, Zenta Nakajima, and Hiroo Taguchi, eds., Financial Stability in a

Changing Environment. New York: St. Martin's Press, 1995.

. "Issues in the Design of Monetary Policy Rules," in John

B. Taylor and Michael Woodford, eds., Handbook of Macroeconomics. Amsterdam:

North-Holland Publishing Co., 1999.

McCallum, Bennett T., and Edward Nelson. "Performance of Operational Policy

Rules in an Estimated Semiclassical Structural Model," in John B. Taylor, ed., Monetary

Policy Rules. Chicago: University of Chicago Press for NBER, 1999.

. "Nominal Income Targeting in an Open-Economy

Optimizing Model,” Journal of Monetary Economics, vol. 43 (June 1999), pp. 553-578.

Meltzer, Allan H. "Limits of Short-run Stabilization Policy,” Economic Inquiry

vol. 25 (1987), pp. 1-14.

. "The Transmission Process," in The Monetary Transmission

Process: Recent Developments and Lessons for Europe." London: Macmillan Publishers,

Ltd., for Deutsche Bundesbank, 1999 (forthcoming).

Orphanides, Athanasios. "Monetary Policy Rules Based on Real-Time Data,"

Finance and Economics Discussion Series 1998-03, Federal Reserve Board, 1998. . "The Quest for Prosperity Without Inflation," Working Paper,

Federal Reserve Board, May 1999.

Stuart, Alison. "Simple Monetary Policy Rules," Bank of England Quarterly

Bulletin, vol. 36 (August 1996), pp. 281-287. 
Svensson, Lars E. O. "Inflation Targeting as a Monetary Policy Rule," Journal of Monetary Economics, vol.43 (June 1999), pp. 607-654.

Taylor, John B. "Discretion Versus Policy Rules in Practice," Carnegie-Rochester Conference Series on Public Policy, vol. 39 (November 1993), pp. 195-214. , ed. Monetary Policy Rules. Chicago: University of Chicago Press for NBER, 1999a. . "A Historical Analysis of Monetary Policy Rules," in John B. Taylor, ed., Monetary Policy Rules. Chicago: University of Chicago Press for NBER, 1999b. 
Figure 1 U.S. Interest Rates, Actual and Implied by Rule (1)

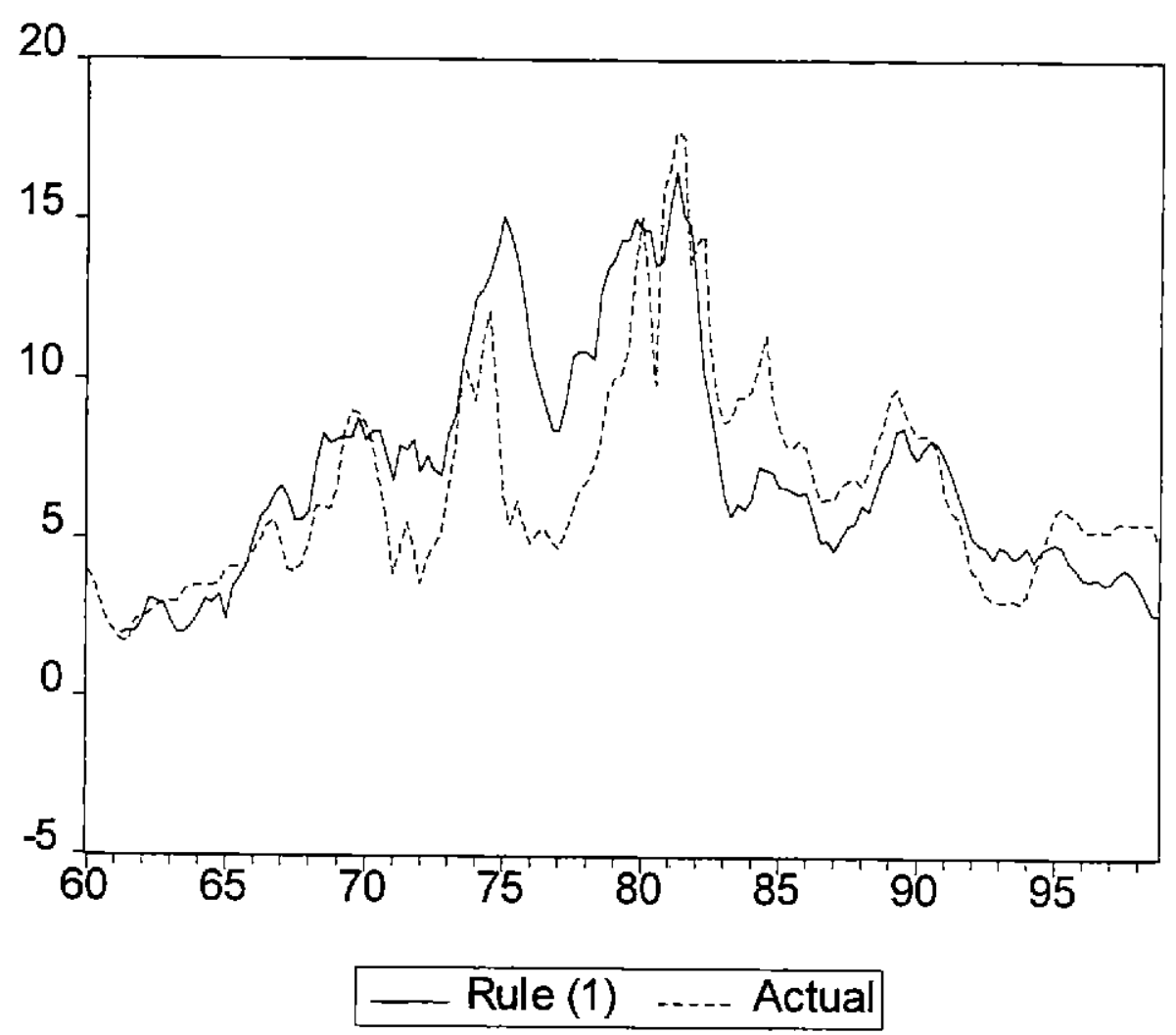

Figure 2 U.S. Base Growth, Actual and Rule (2)

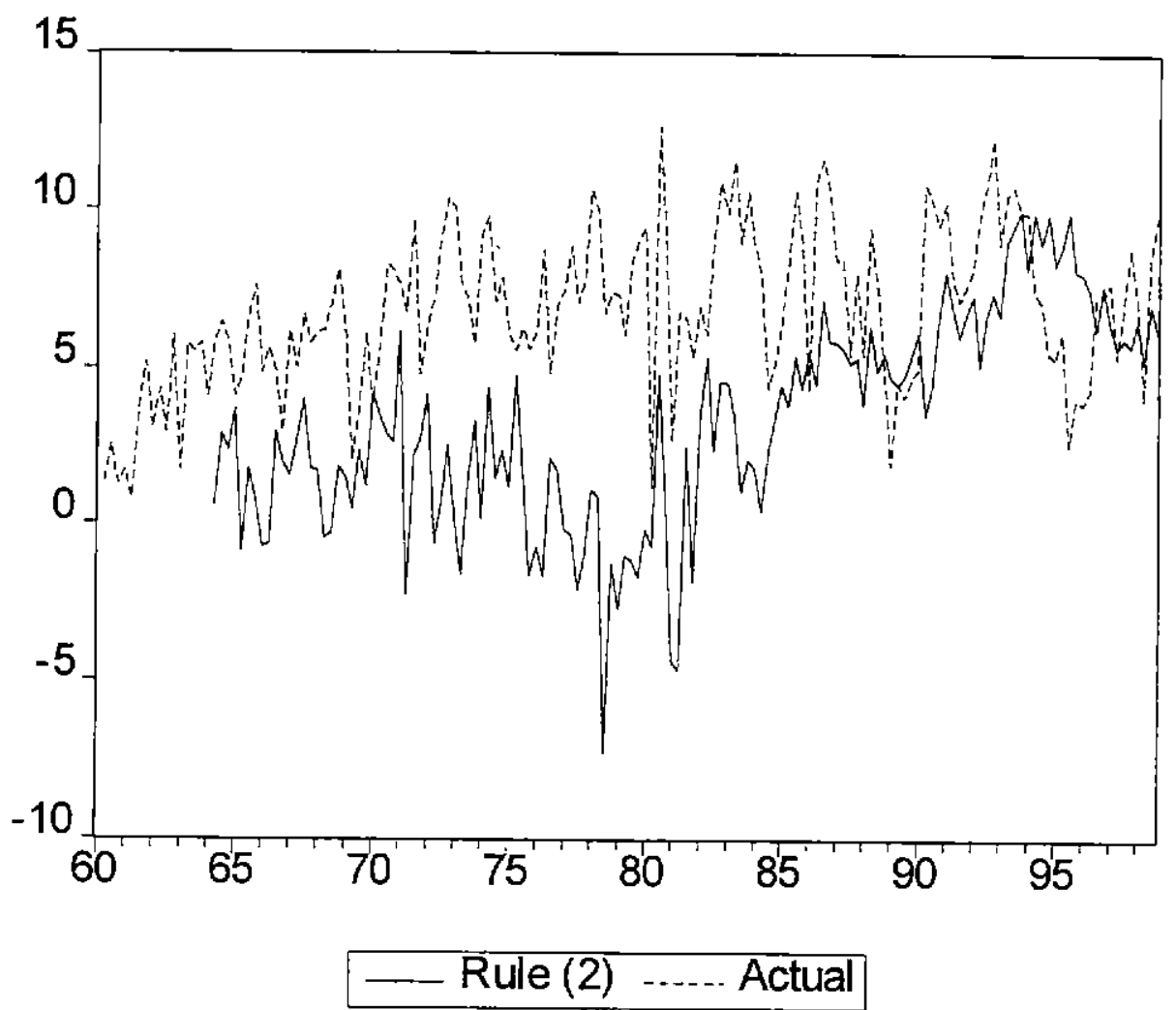


Figure 3 U.S. Base Growth, Actual and Rule (4)

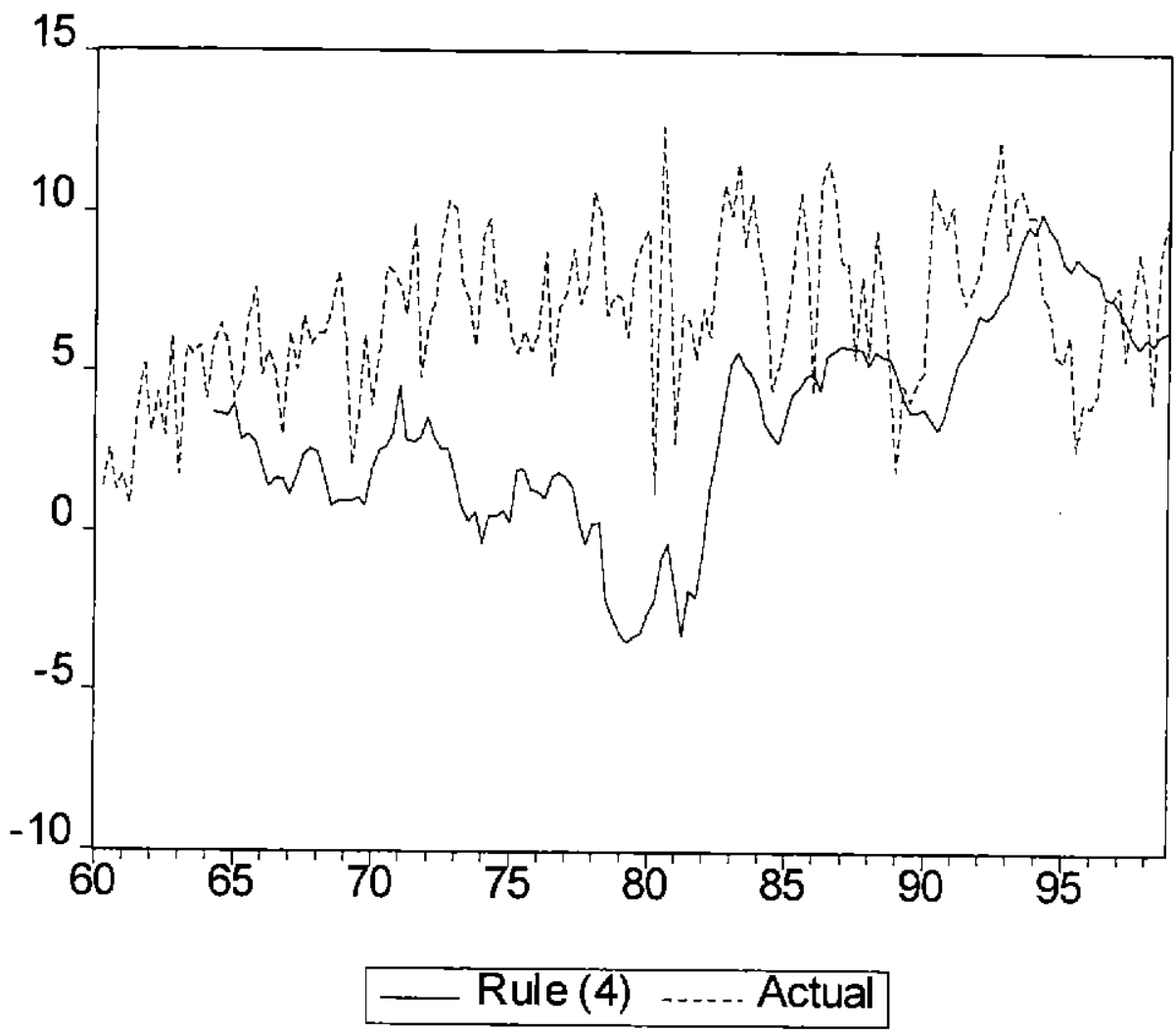

Figure 4 U.S. Interest Rate, Actual and Rule (3)

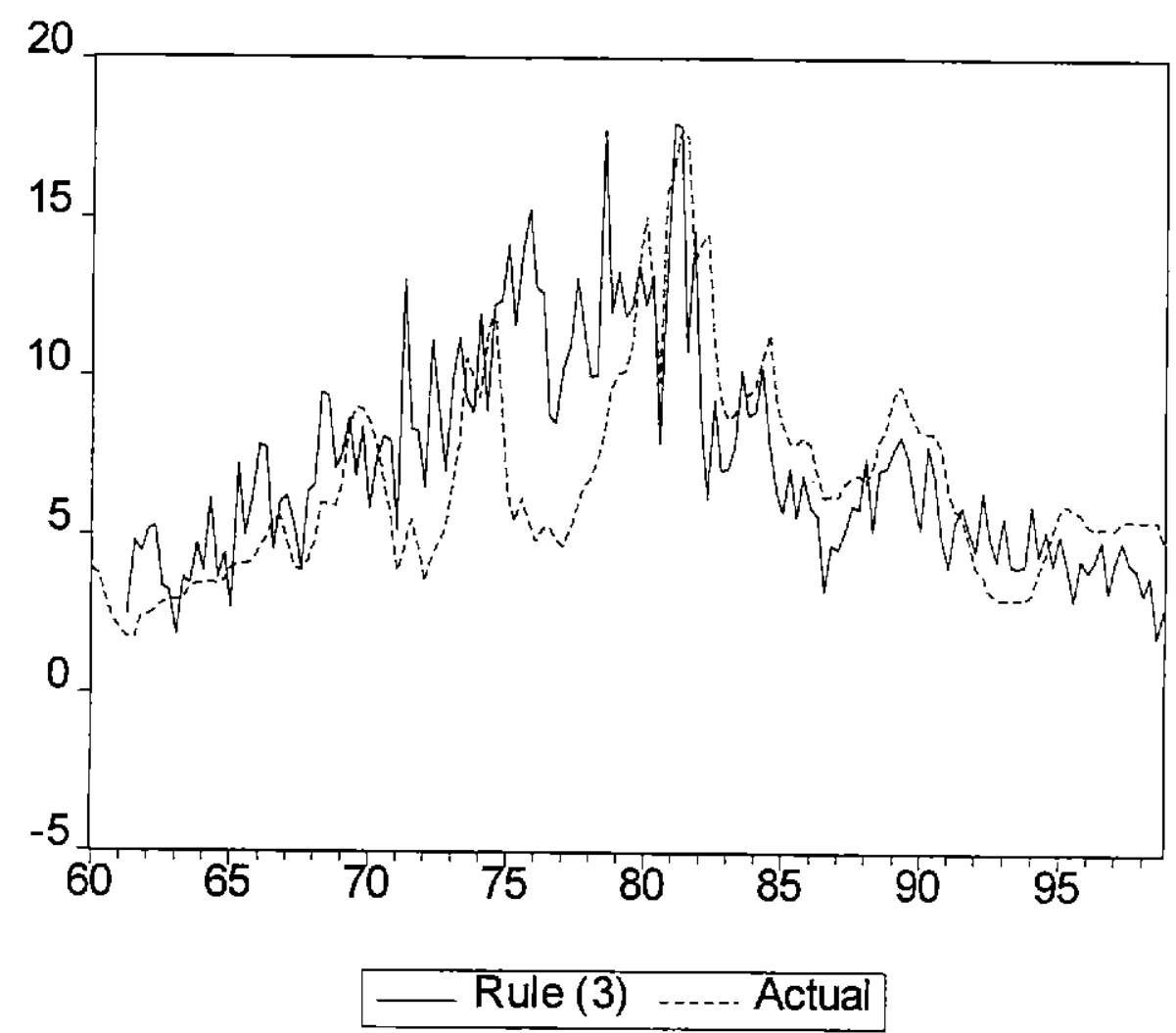


Figure 5 U.K. Interest Rate, Actual and Rule (1)

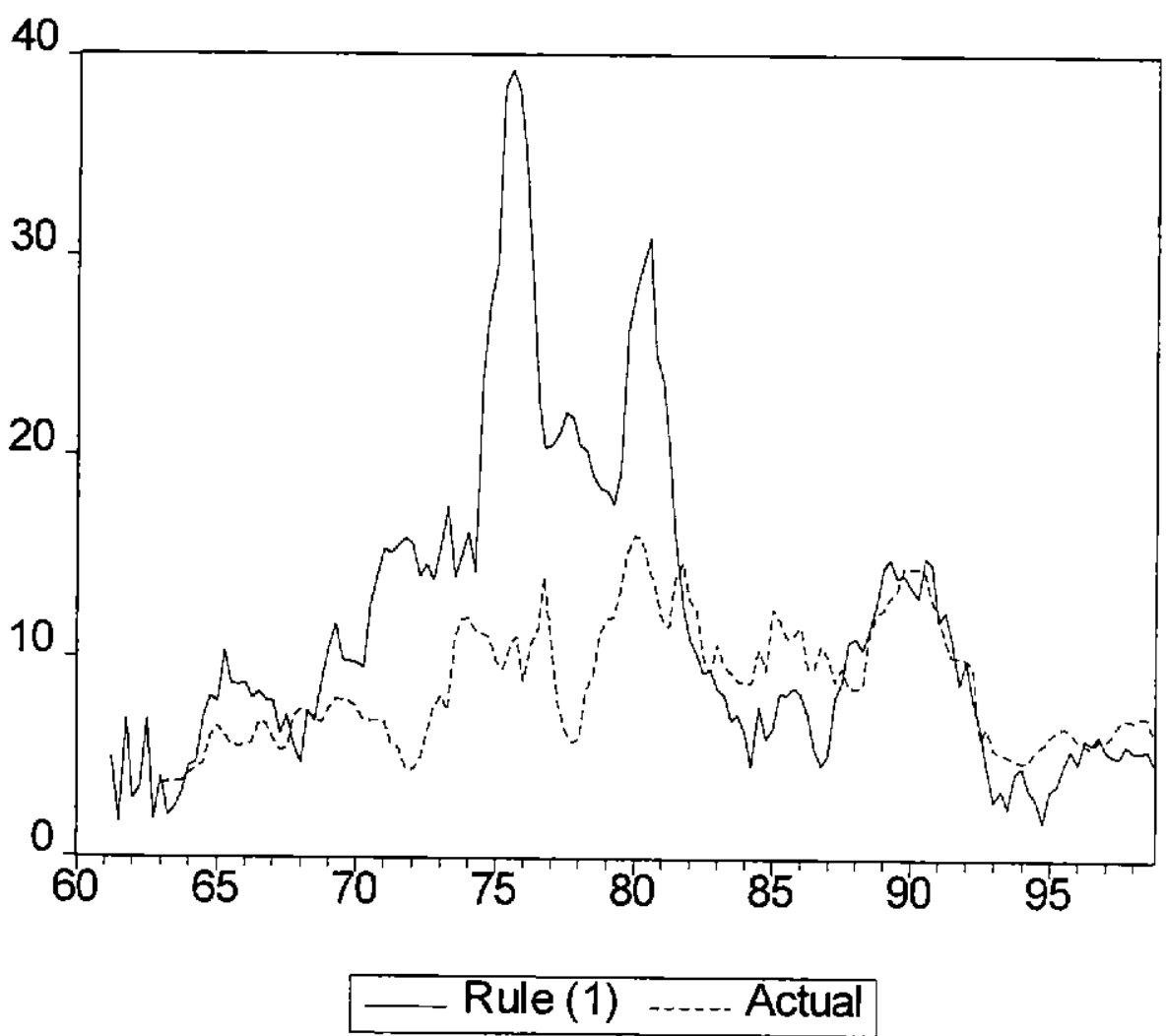

Figure 6 U.K. Base Growth, Actual and Rule (2)

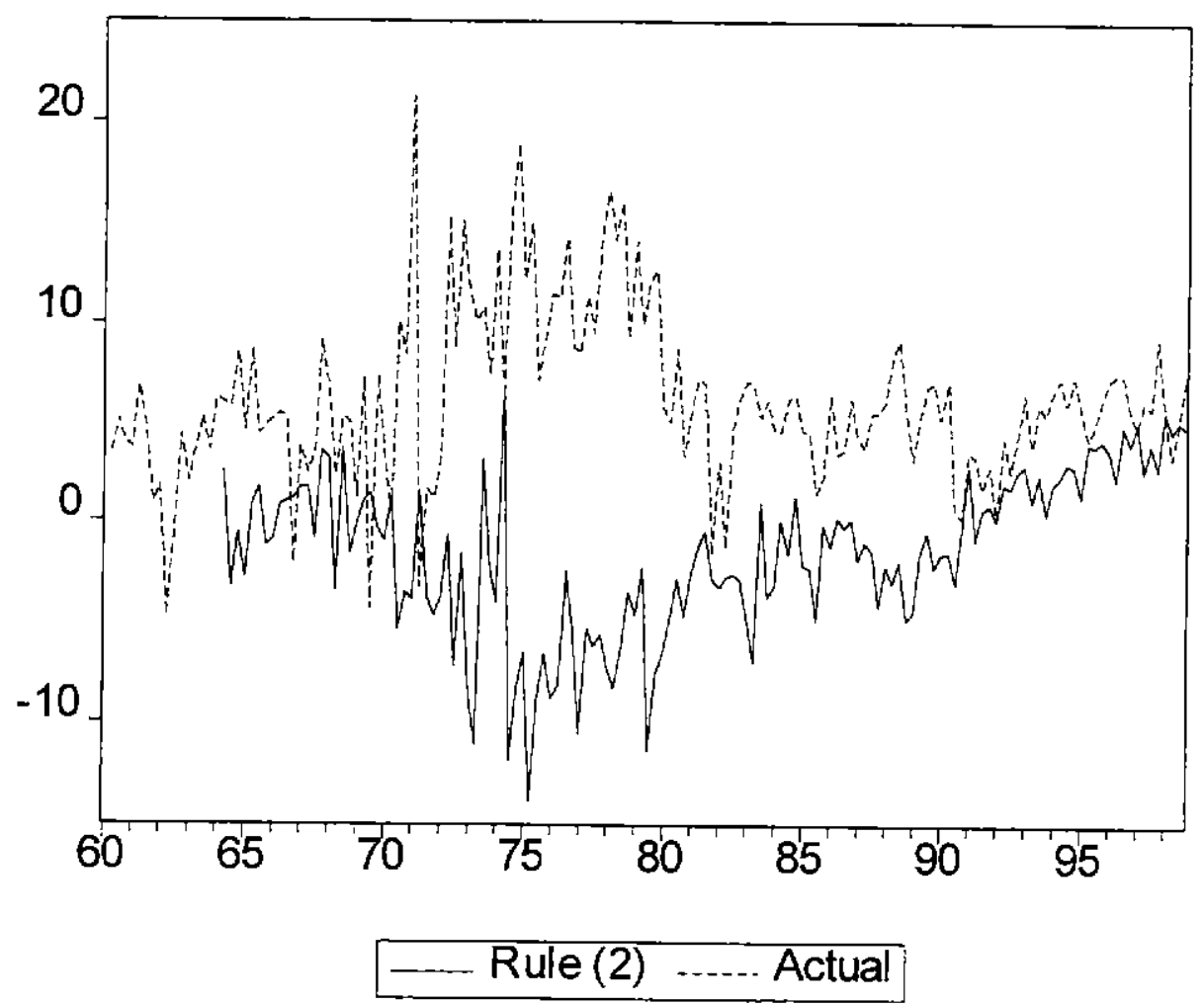


Figure 7 U.K. Base Growth, Actual and Rule (4)

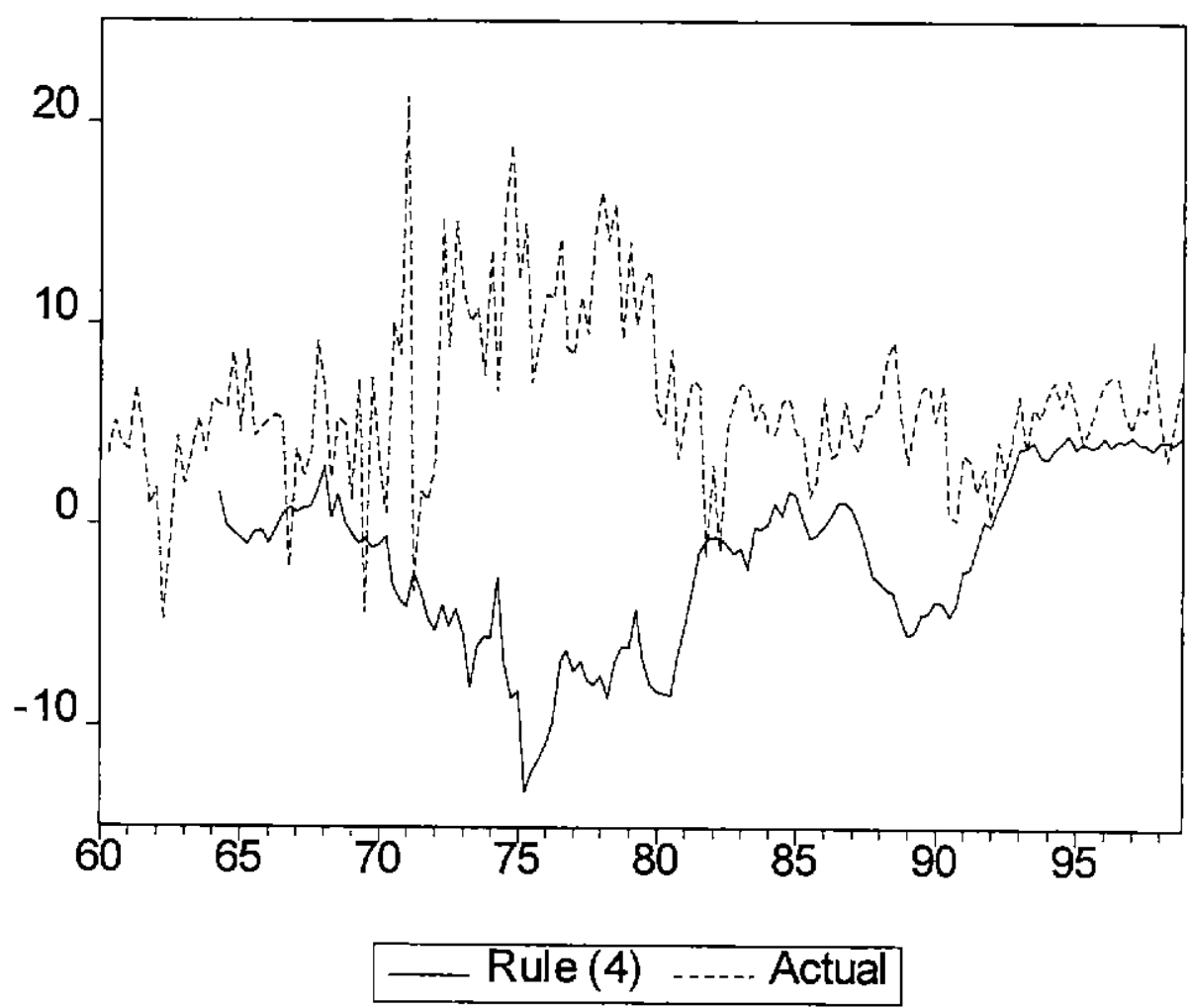

Figure 8 U.K. Interest Rate, Actual and Rule (3)

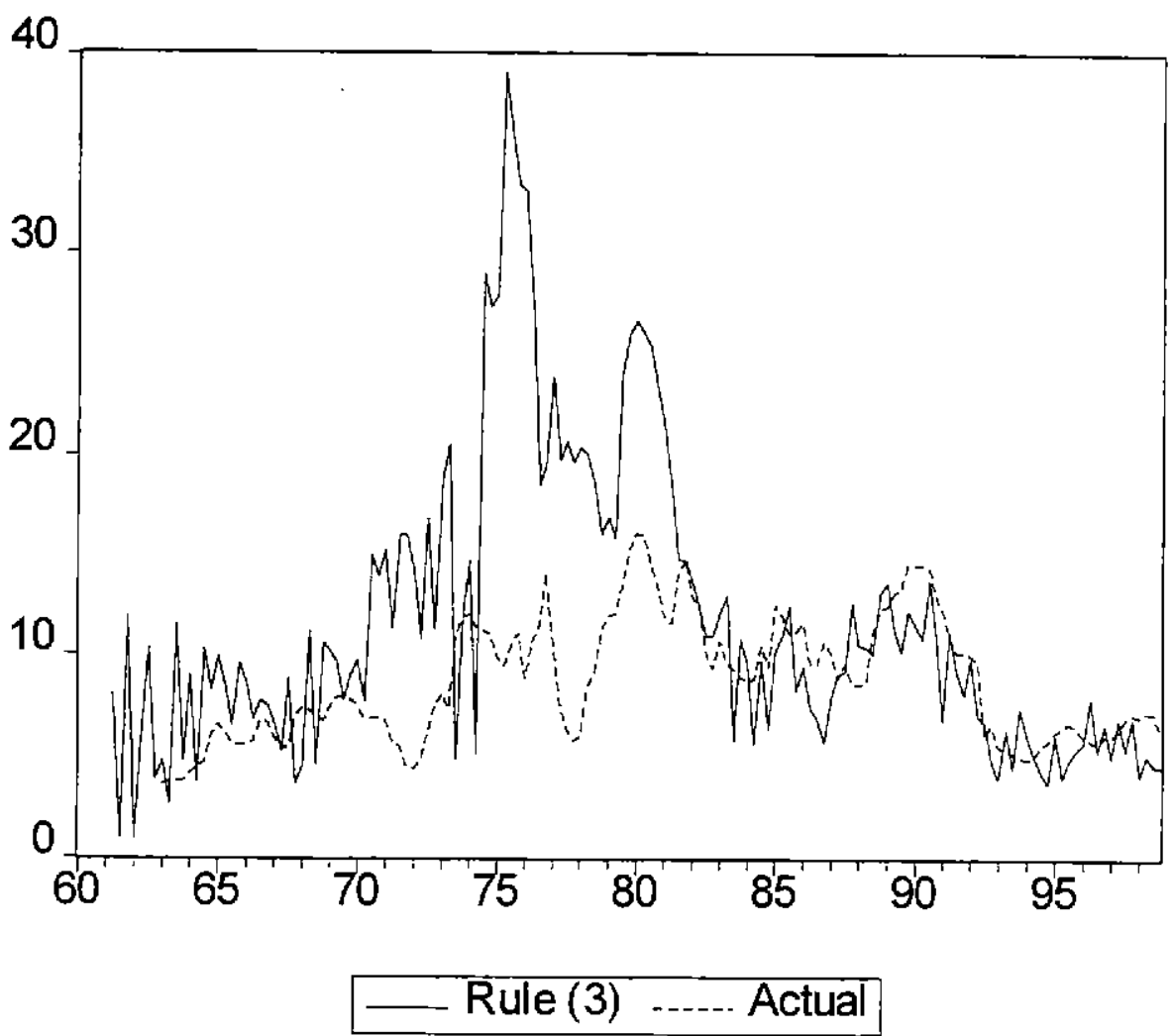


Figure 9 Japan Interest Rate, Actual and Rule (1)

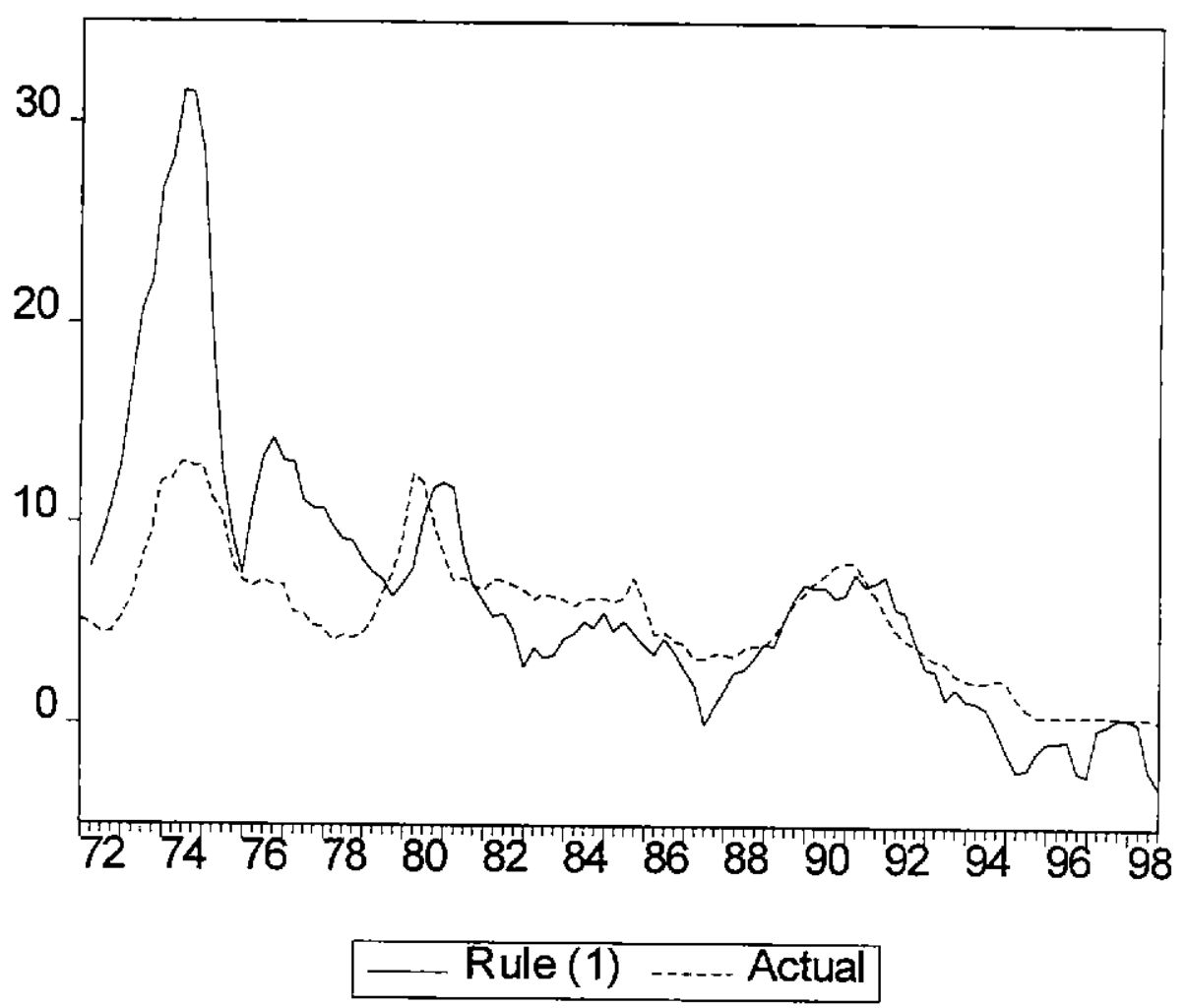

Figure 10 Japan Base Growth, Actual and Rule (2)

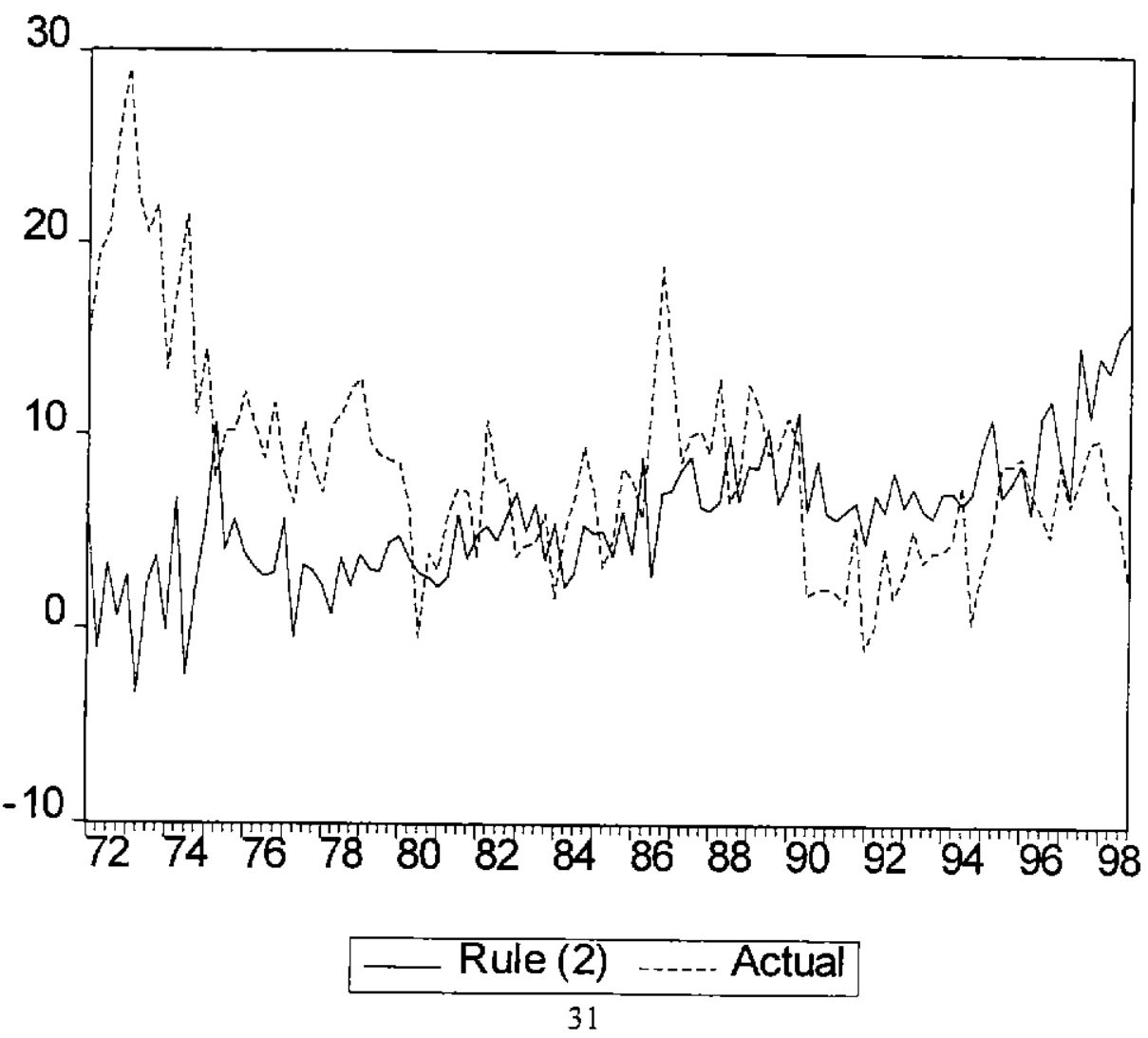


Figure 11 Japan Base Growth, Actual and Rule (4)

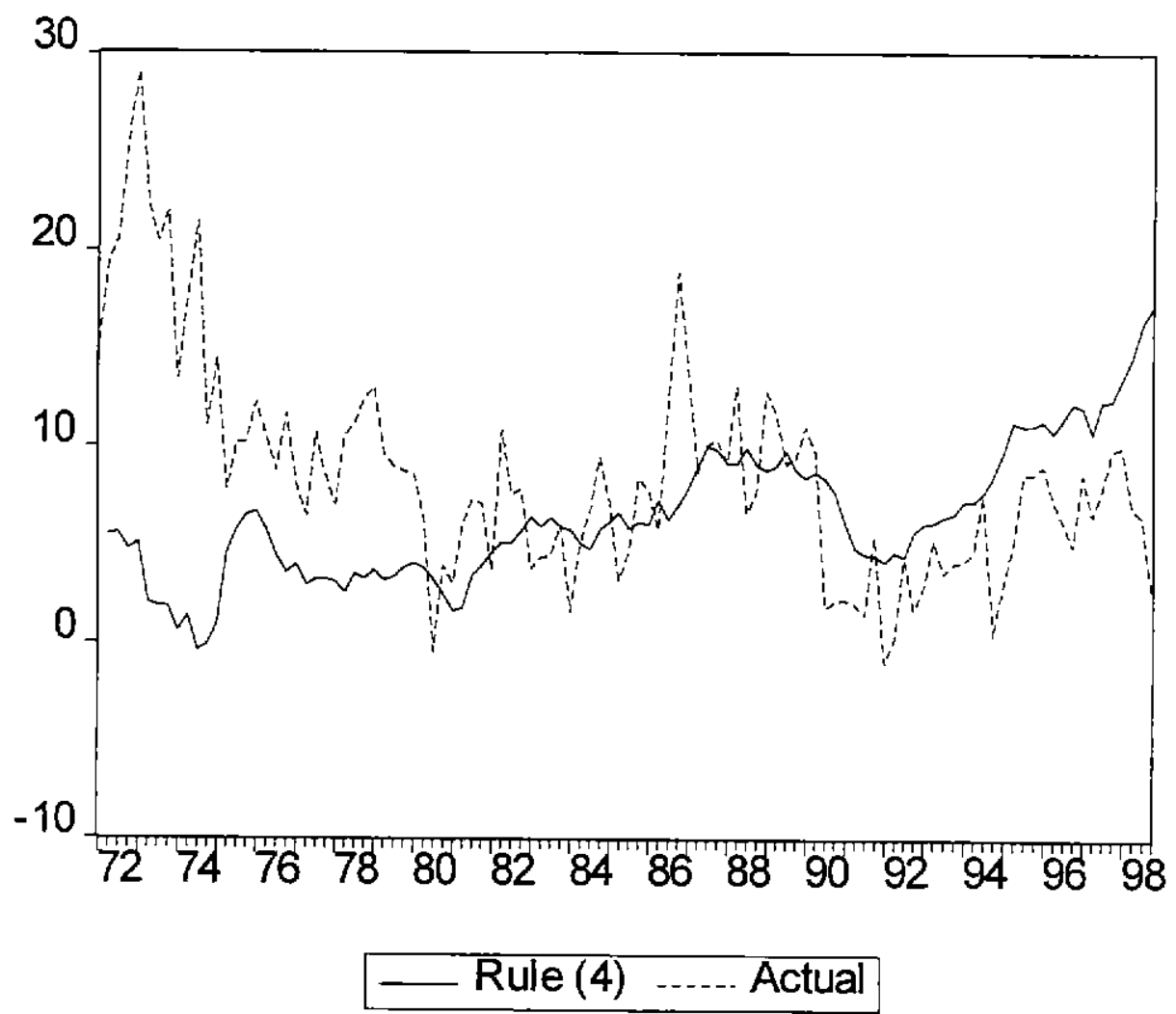

Figure 12 Japan Interest Rate, Actual and Rule (3)

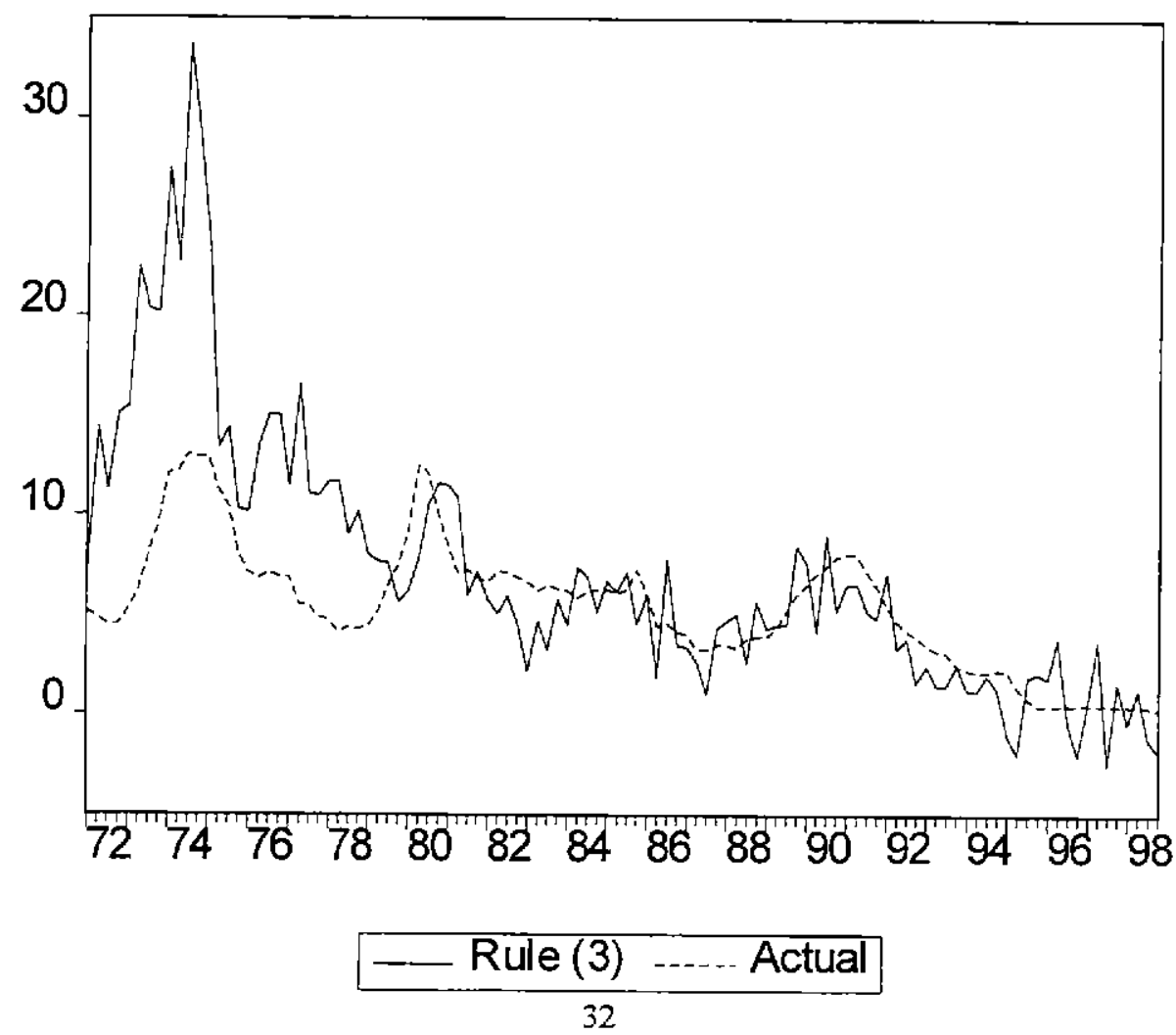


Figure 13 U.S. Rule (1) with Output Gap Based on Log-linear Detrending 1960-1998

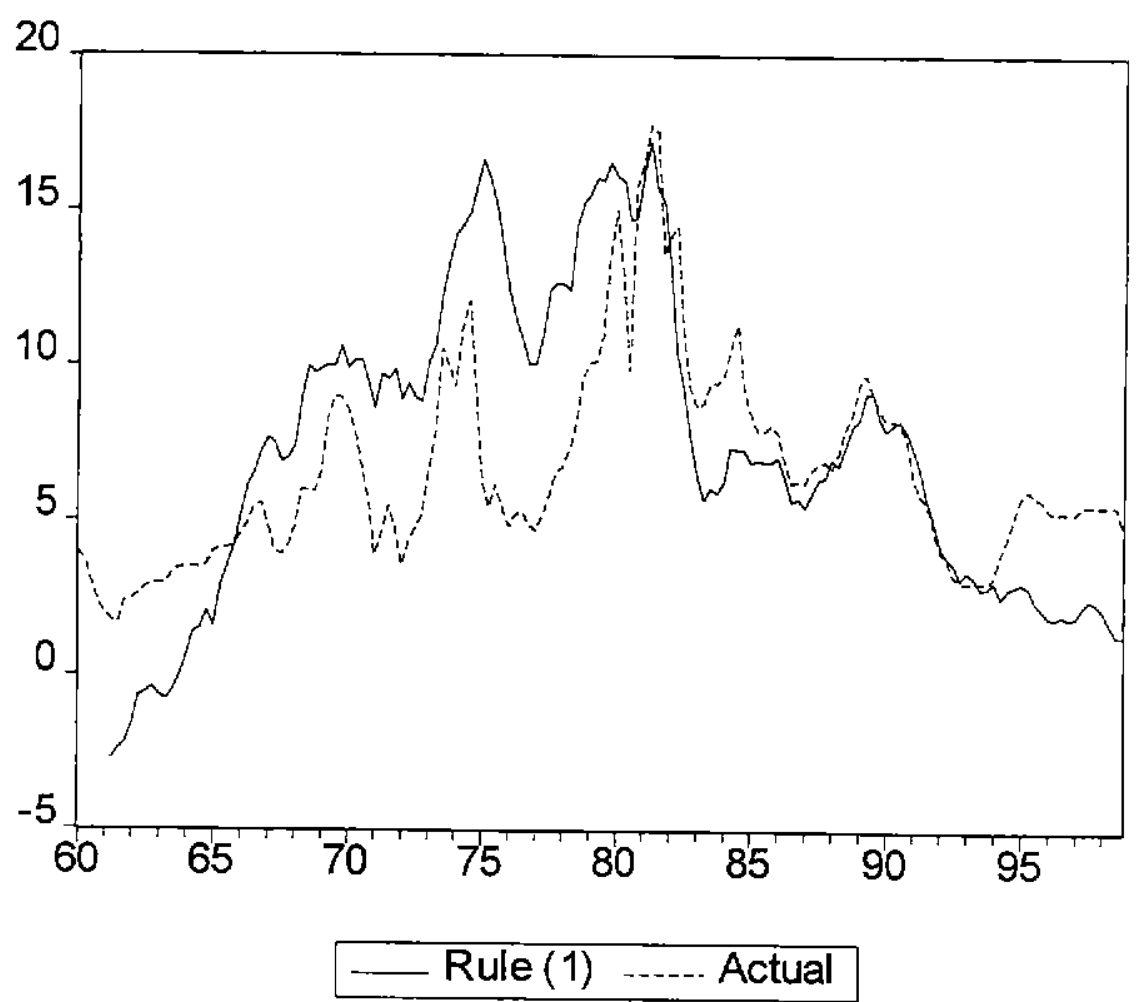

Figure 14 U.S. Output Gaps Based on HP Filter and Log-linear Detrending 1960-1998 and 1980-1998

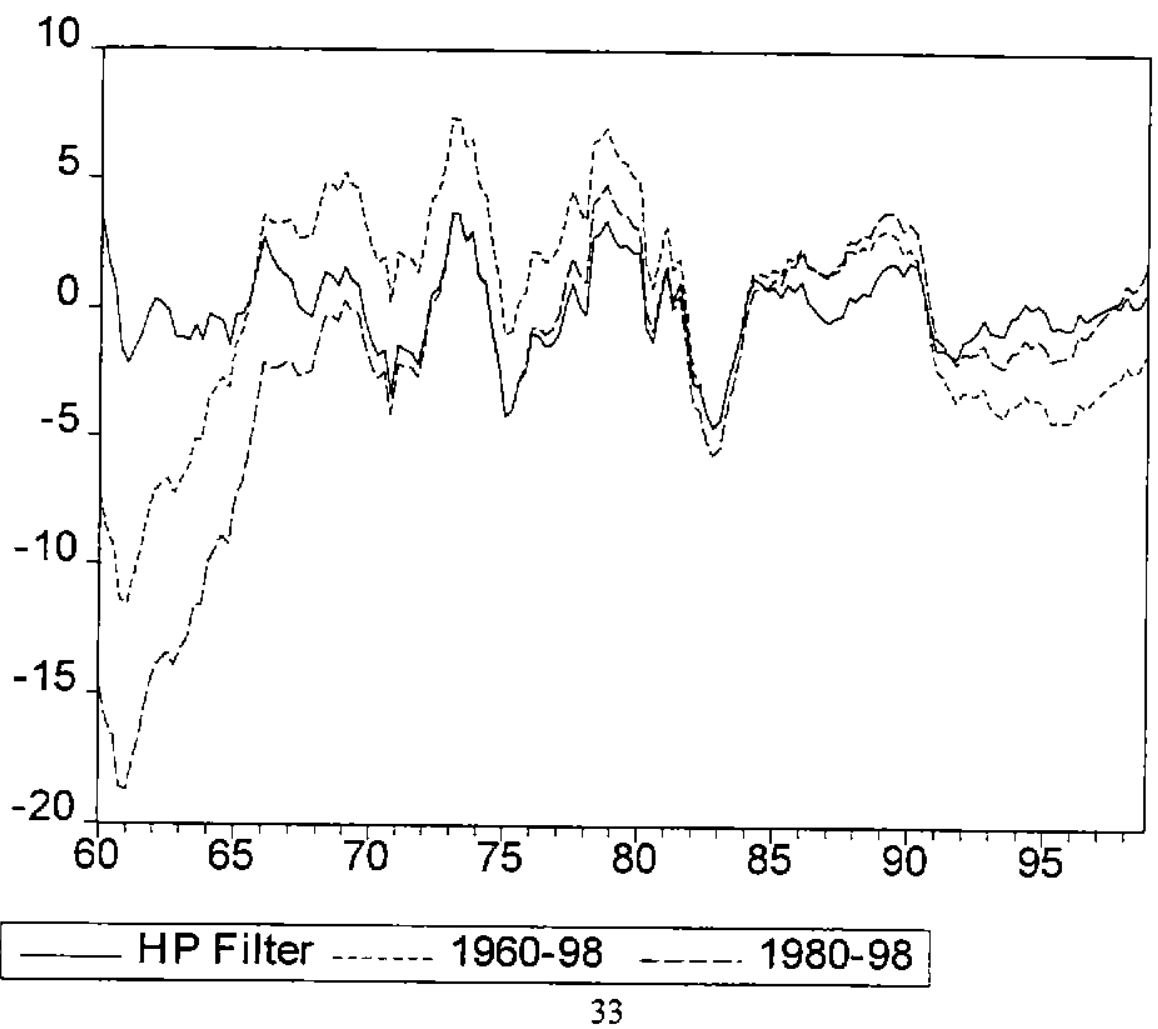


Figure 15 U.S. Gap Measures Based on Log-Quadratic Detrending, 1960-1998 and 1980-1998

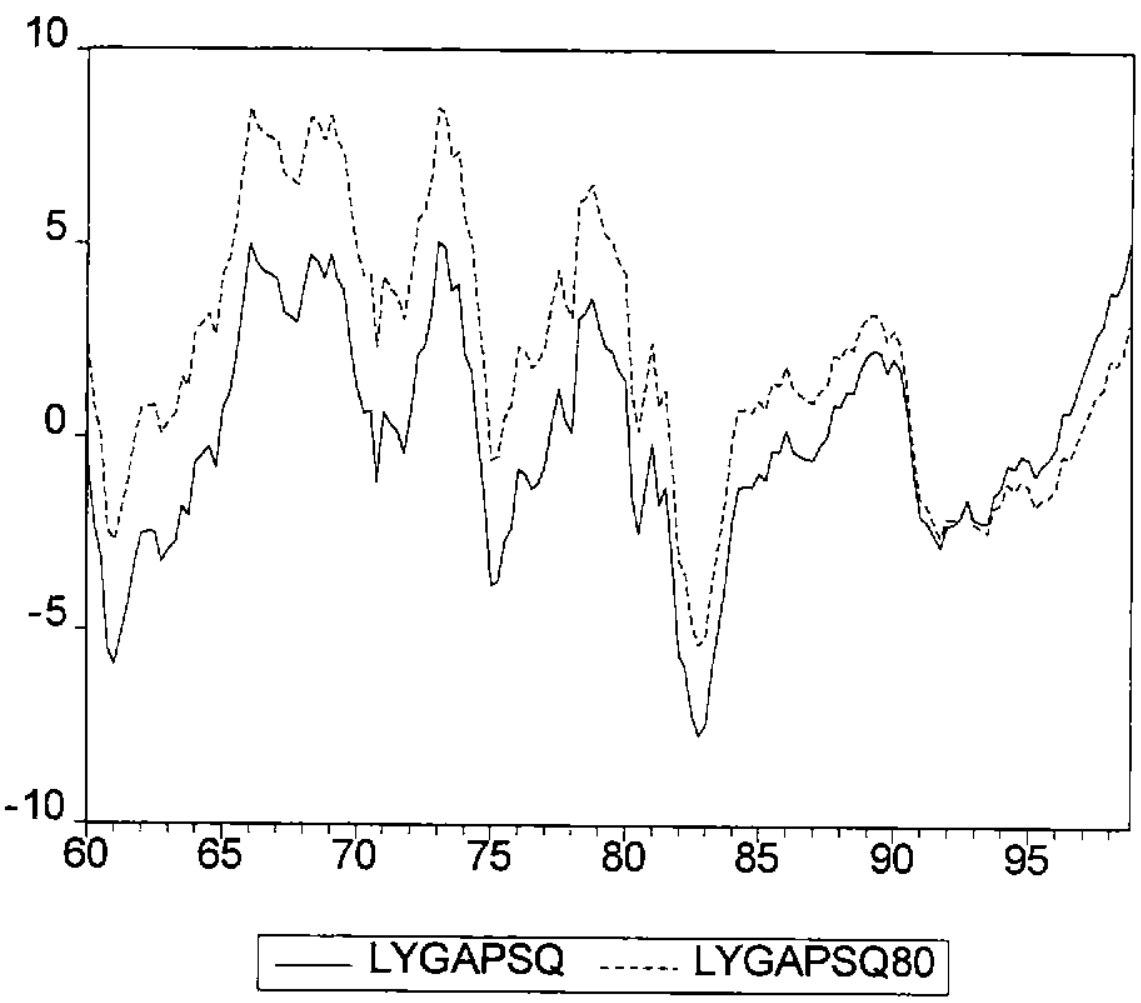

Figure 16 U.S. Real GNP and HP Trend, 1921-1939

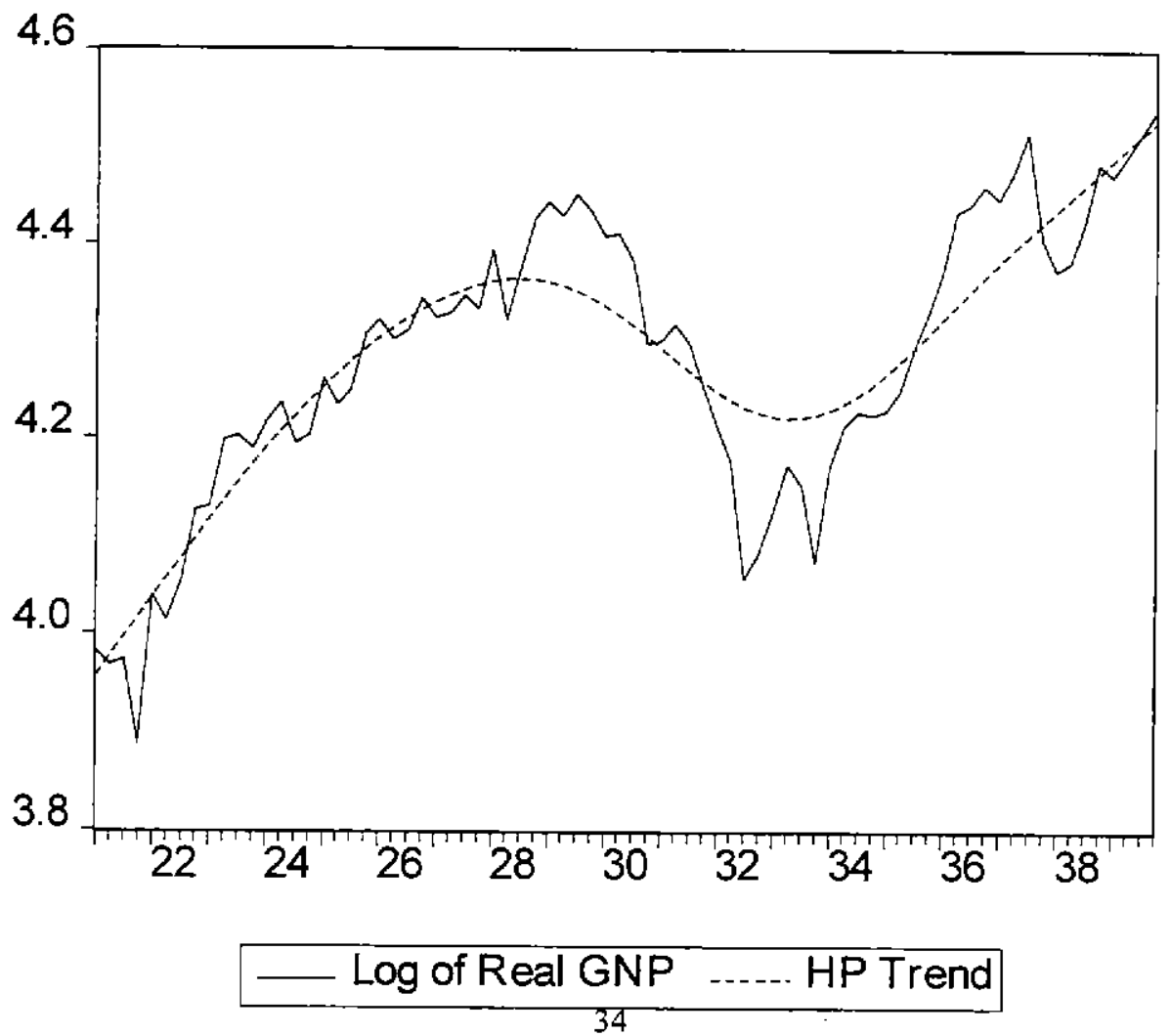


Figure 17 U.S. Interest Rate, Actual and Rule (5)

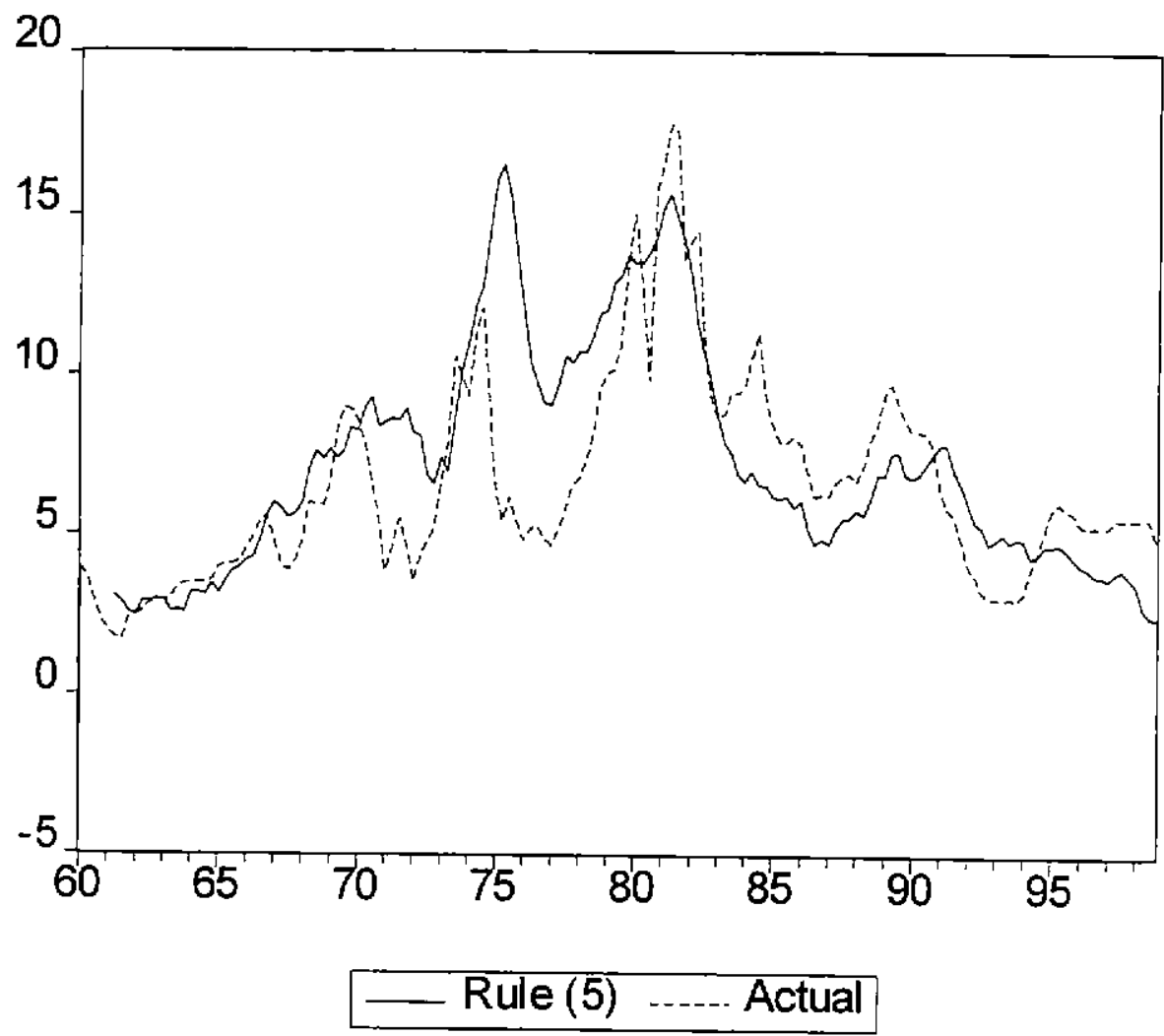

Figure 18 U.S. Base Growth, Actual and Rule (6)

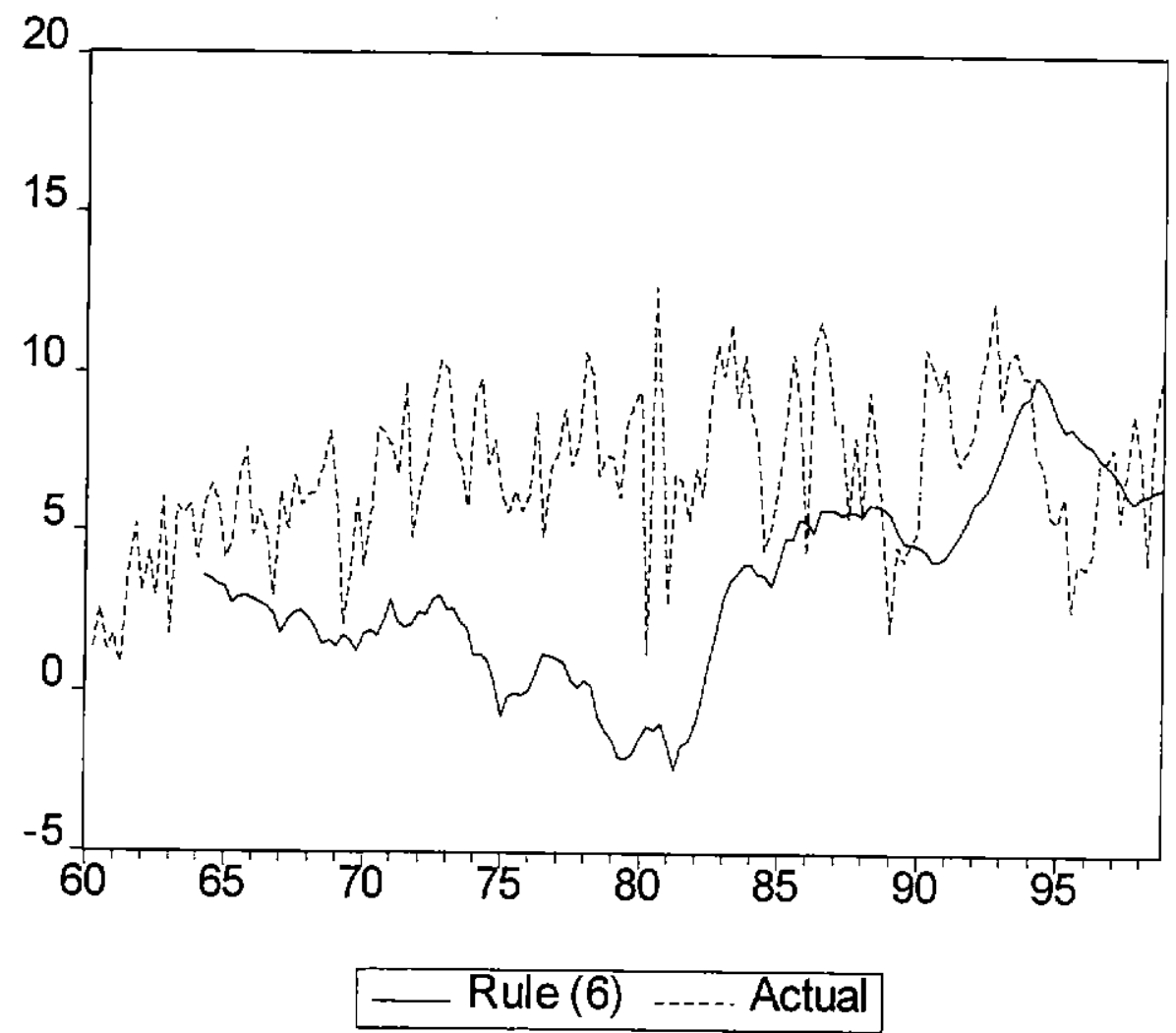


Figure 19 U.K. Interest Rate, Actual and Rule (5)

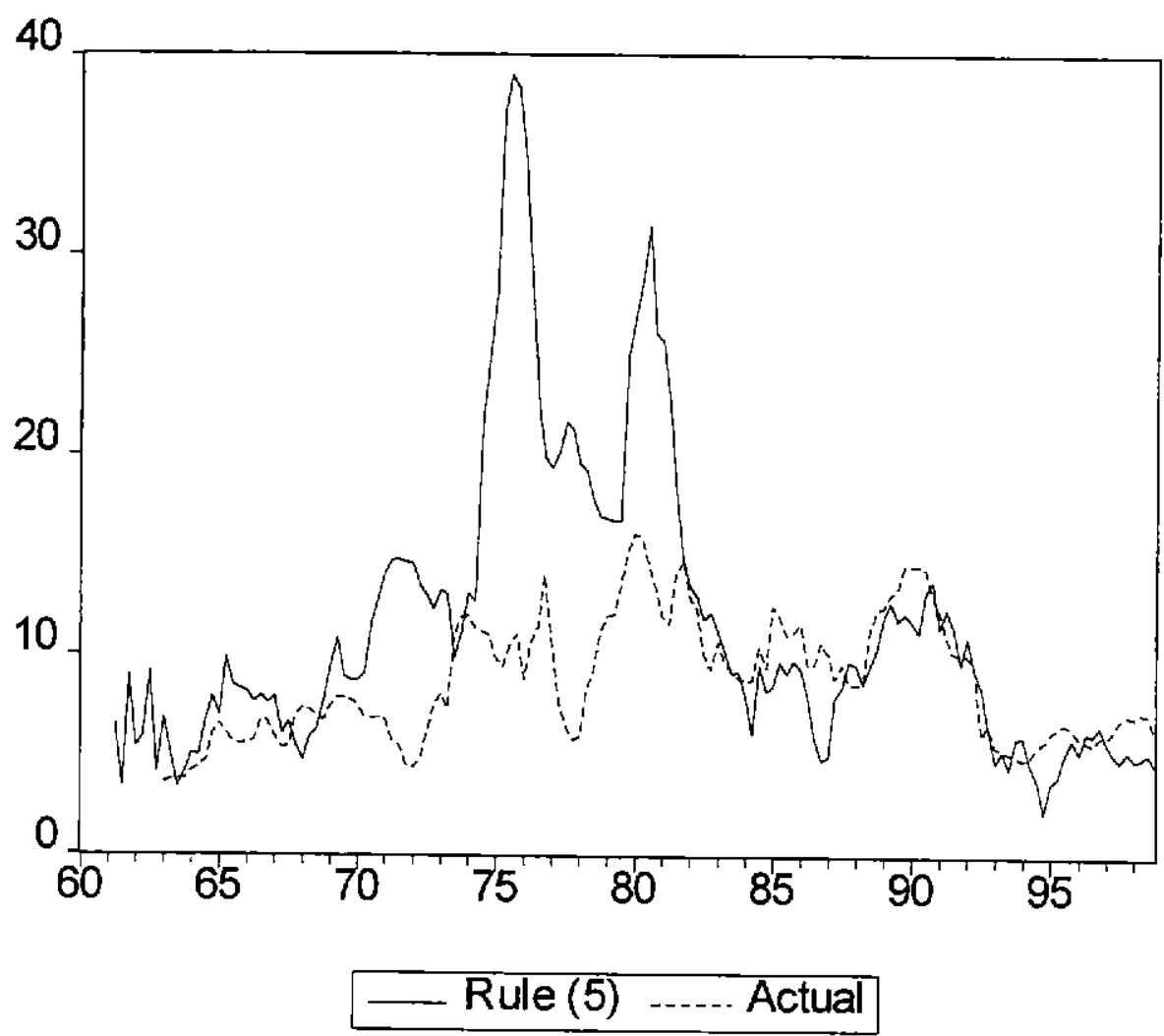

Figure 20 U.K. Base Growth, Actual and Rule (6)

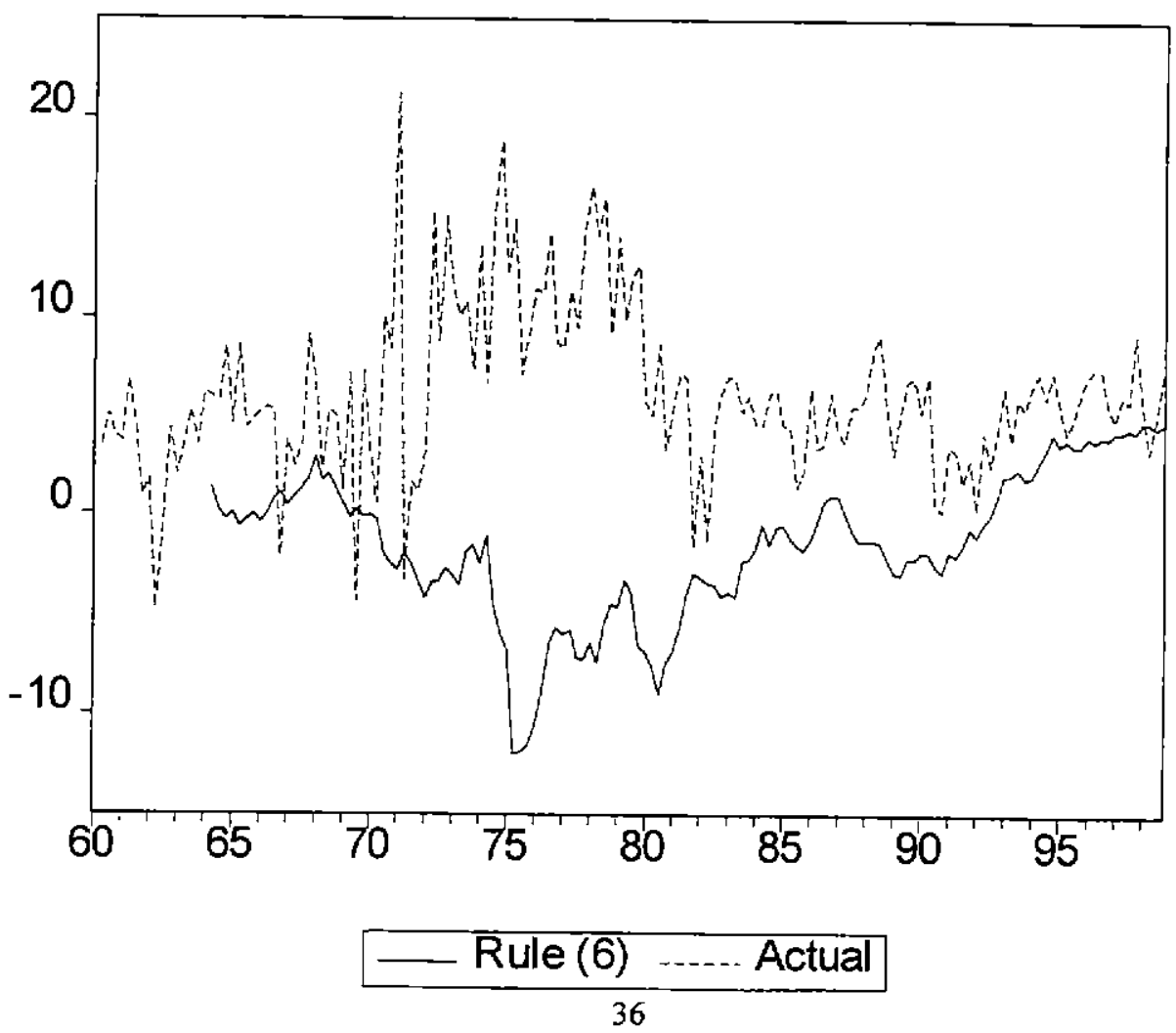


Figure 21 Japan Interest Rate, Actual and Rule (5)

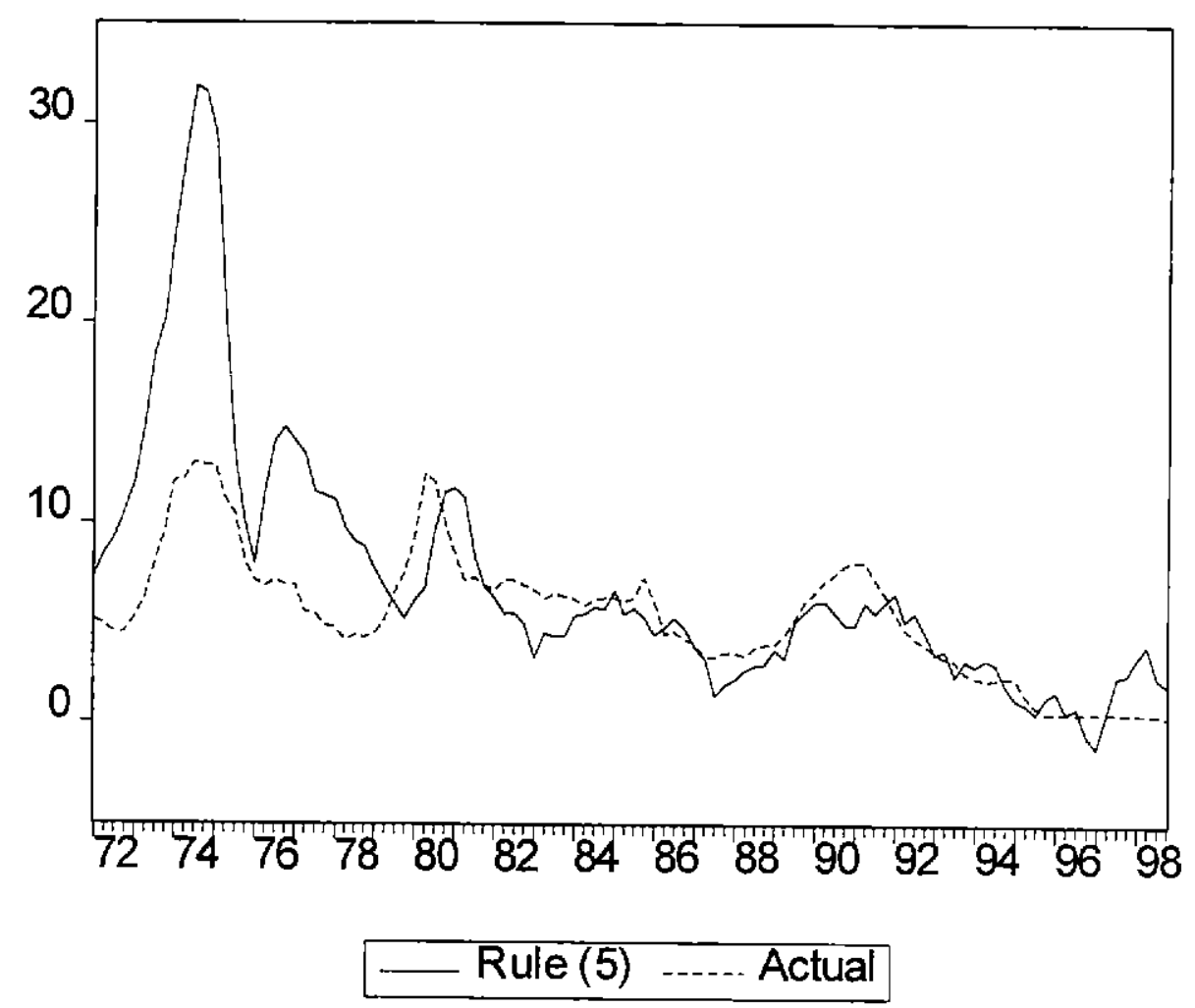

Figure 22 Japan Base Growth, Actual and Rule (6)

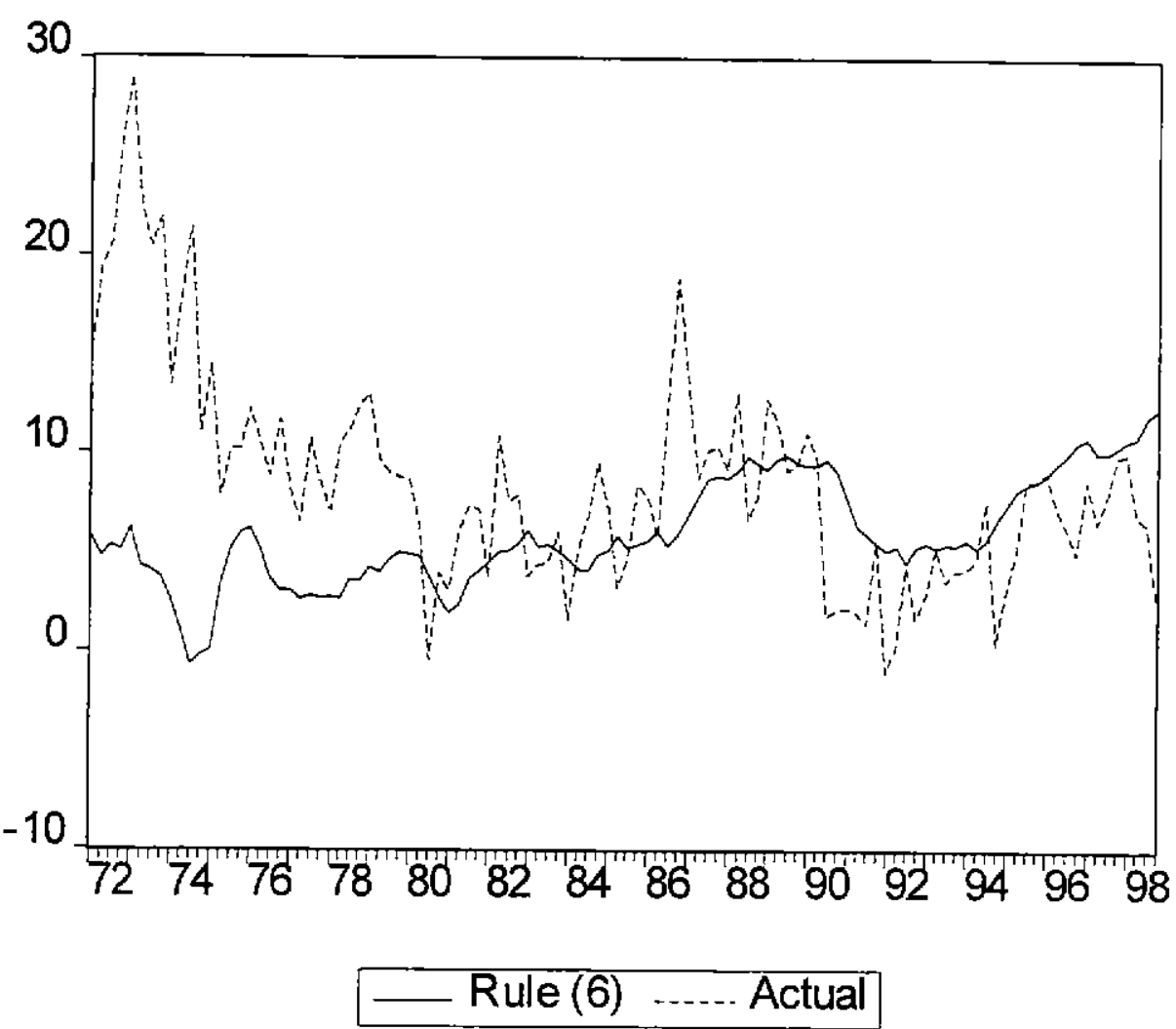


Figure 23 U.S. Interest Rate, Actual and Rule With Averaged Nominal Income Growth

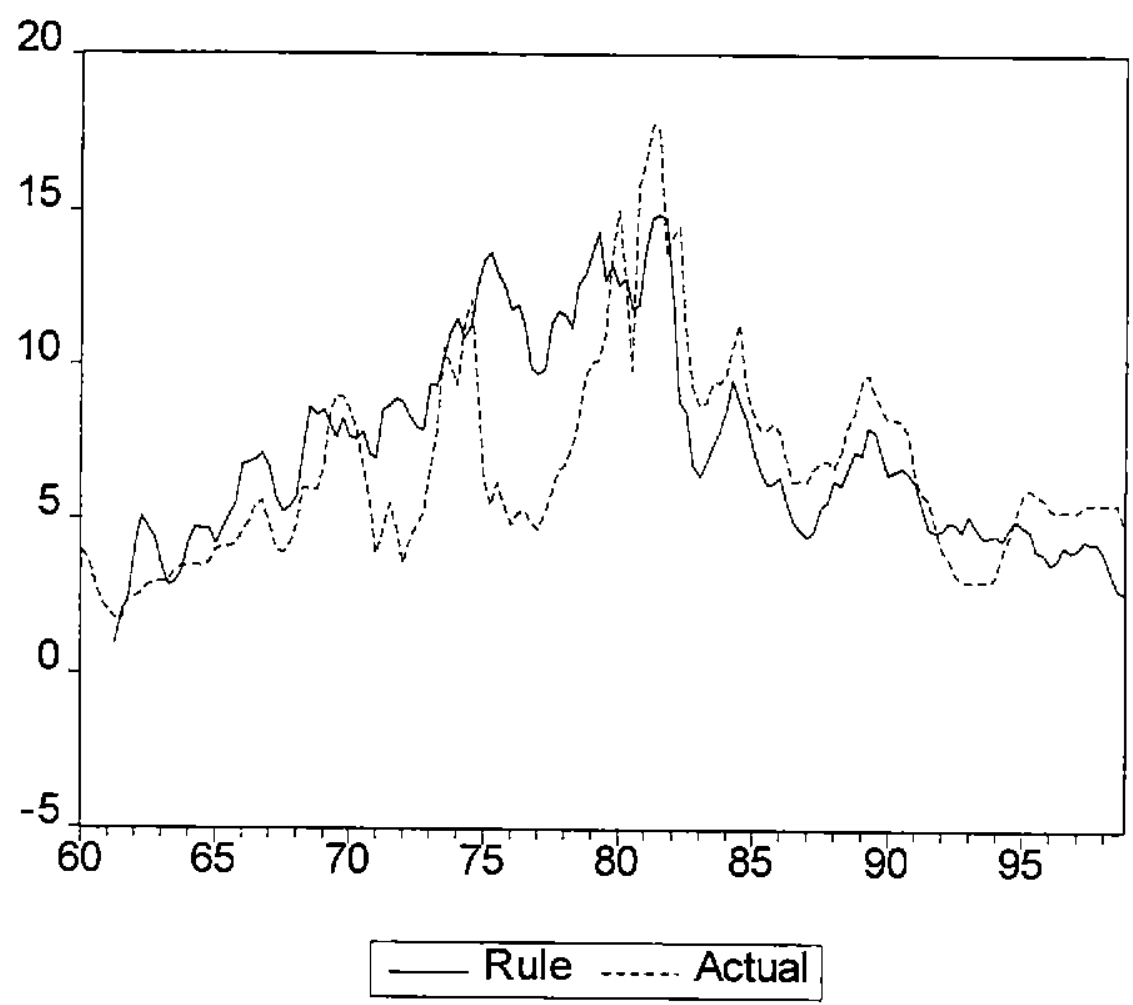

Figure 24 U.S. Base Growth, Actual and Rule With Averaged Nominal Income Growth

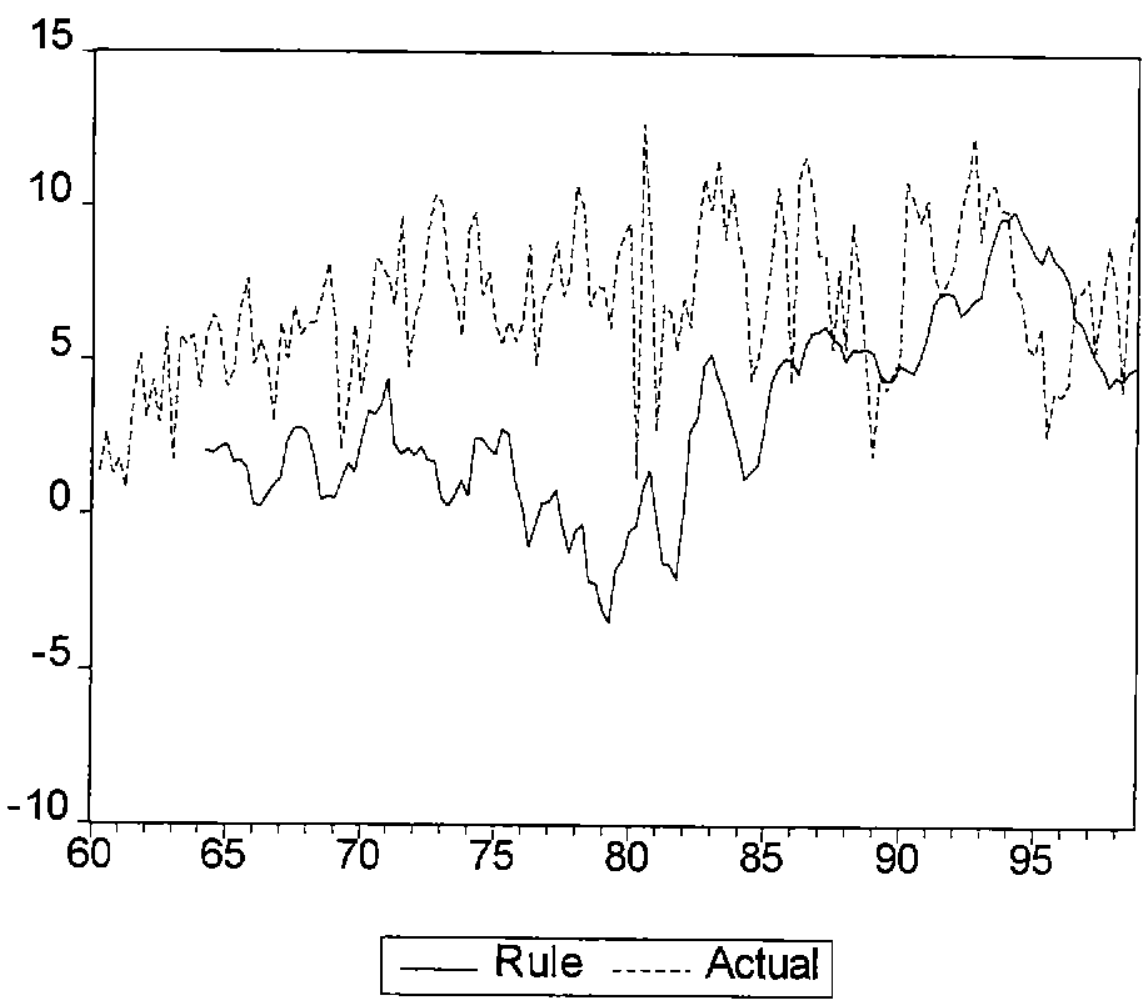


Figure 25 U.K. Interest Rate, Actual and Rule With Averaged Nominal Income Growth

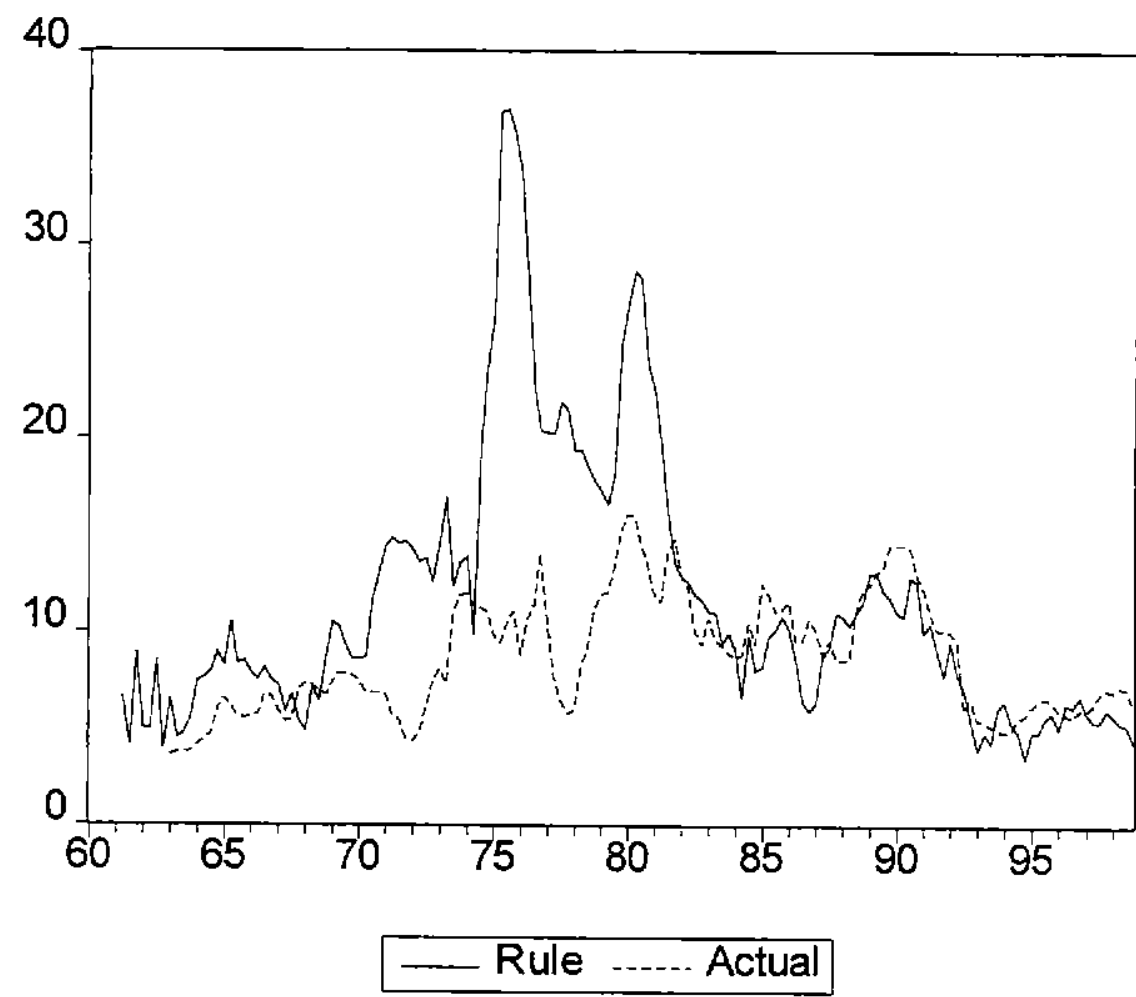

Figure 26 U.K. Base Growth, Actual and Rule With Averaged Nominal Income Growth

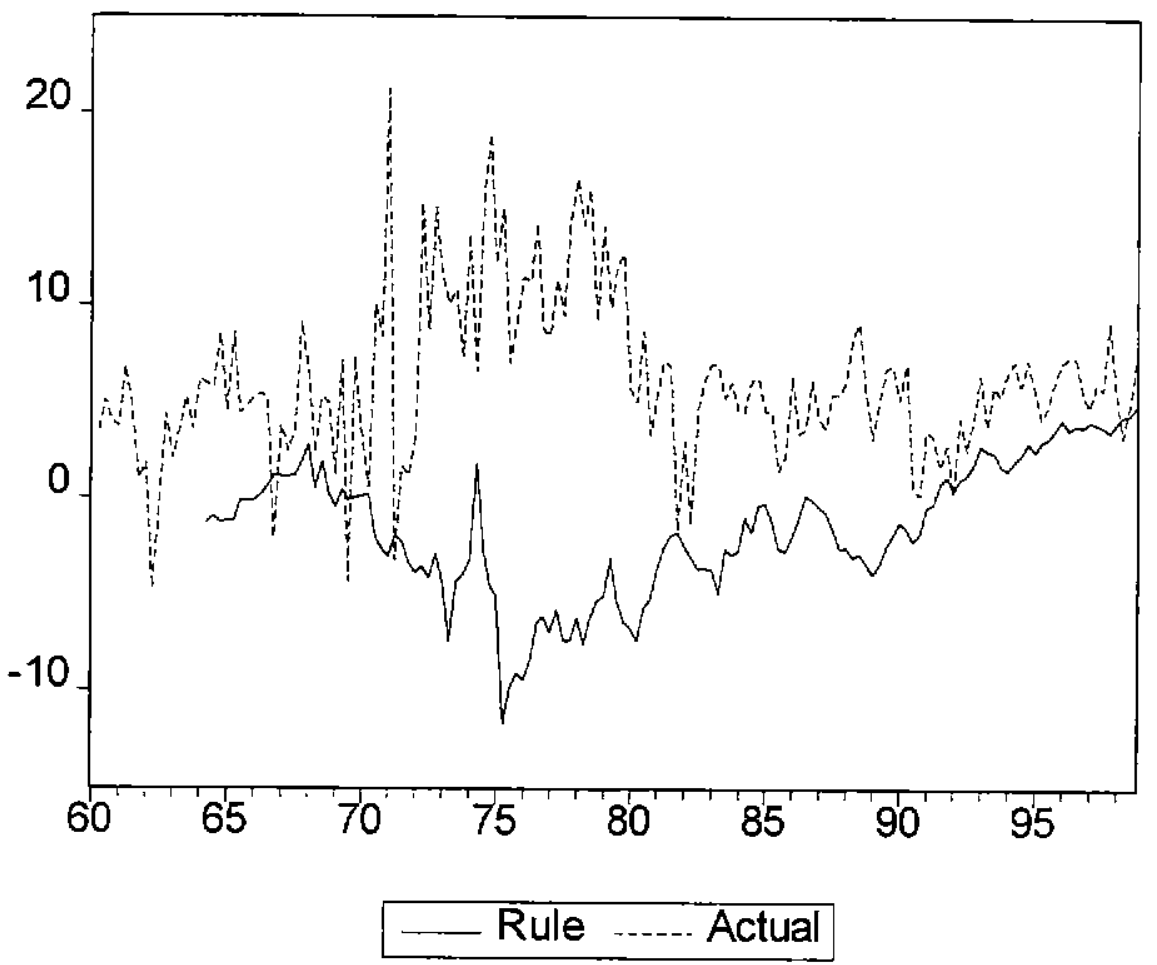


Figure 27 Japan Interest Rate, Actual and Rule With Averaged Nominal Income Growth

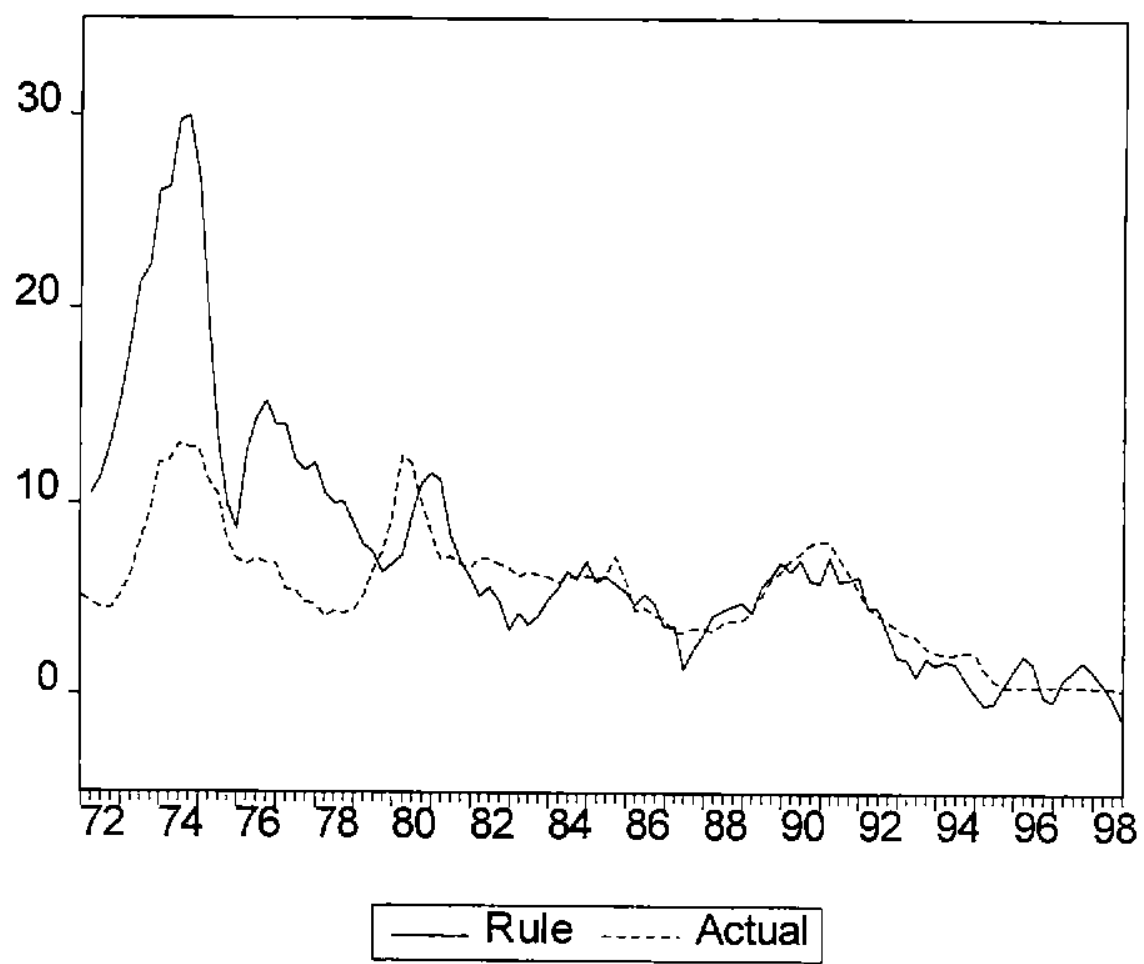

Figure 28 Japan Base Growth, Actual and Rule With Averaged Nominal Income Growth

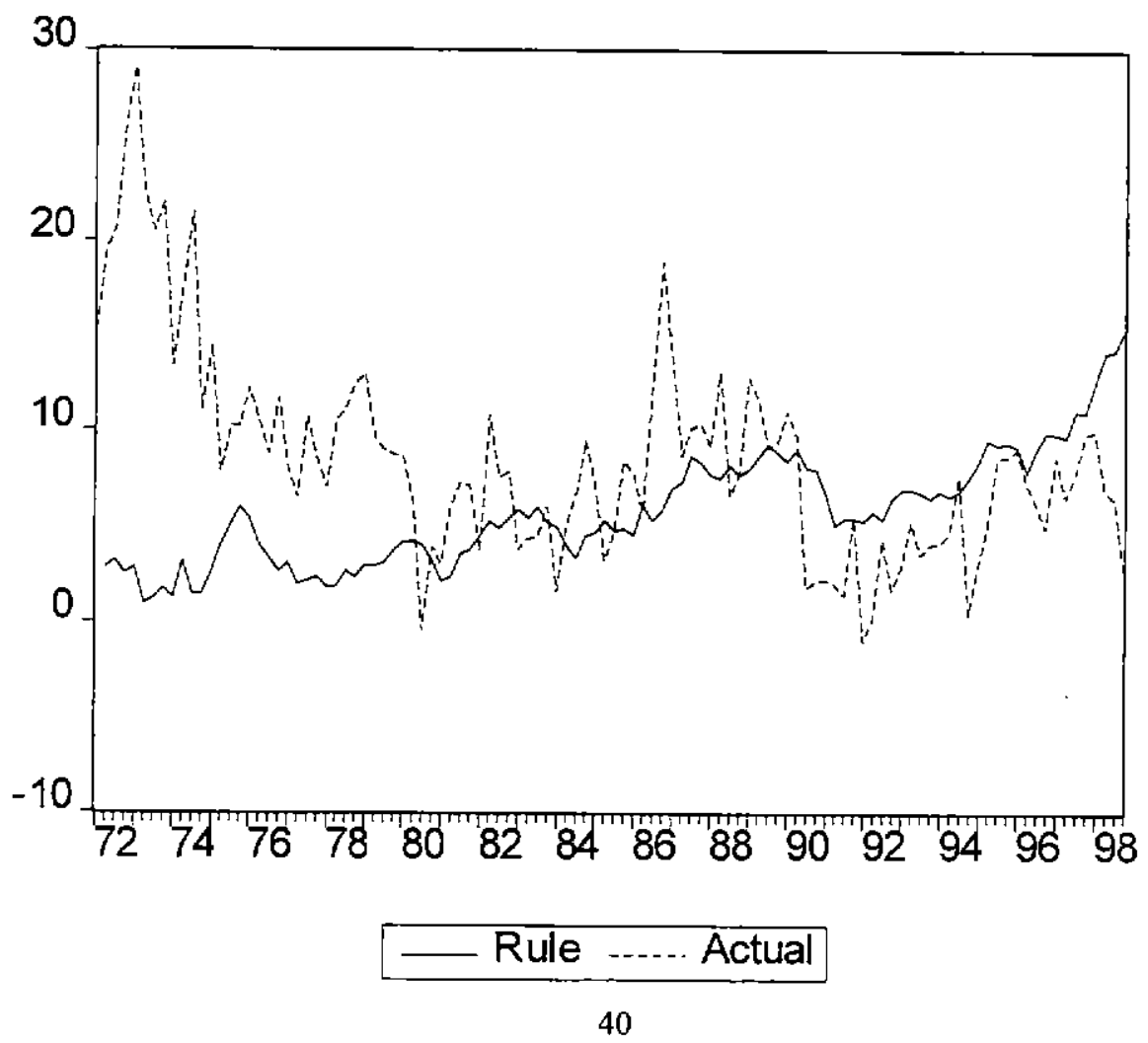

